تأثير استخدام أسلوب التعلم الاتقاني في التعلم والاحتفاظ لبعض

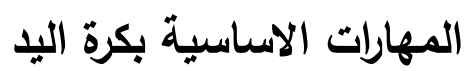

"د/ خالا نبيل محمود خضير

المقدمة ومشكلة البحث:

يعتمد التعلم الحركي على مدى فاعلية الأسـاليب المستخدمة في تعلم

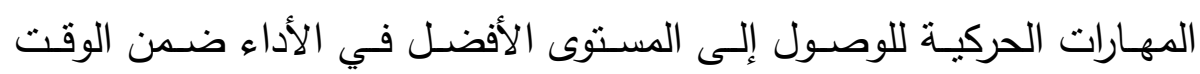

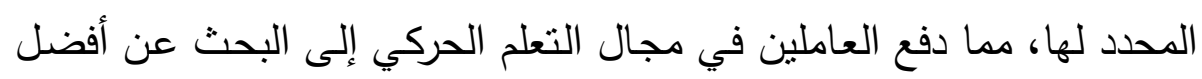
الأساليب التعليمية الحديثة في تحقيق هدف تعلم المهارات الحركية وأثر انتشار التكنولوجيا في حياتتا العامة تأثيراً مباشراً على طرق وأساليب التدريس الحديثة

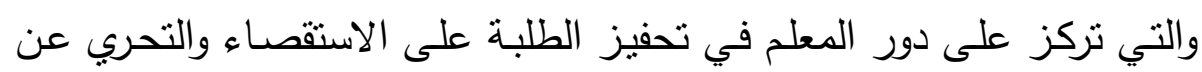
المشكلة والعمل على ايجاد الحلول المناسبة والتركيز على الأهداف الوجدانية والتربوية والسلوكية وتعلم المهارات الأساسية. كما أن للتعلم الحركي دور مهم في جميع نواحي حياتتا للفرد والجماعة

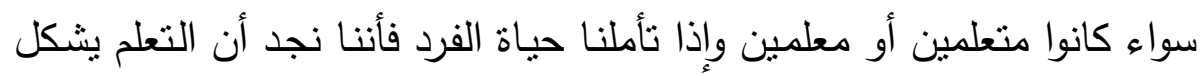
مكانه مهمه على نحو مستمر عبر مراحل العمر المختلفة وللتعلم طرق وأثنال

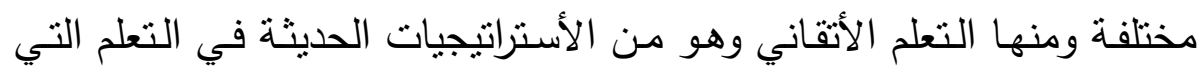

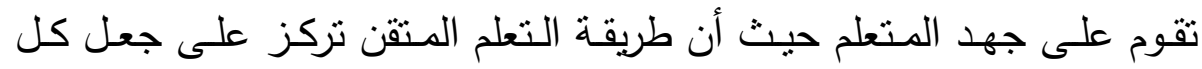
المتعلمين أو غاليبيتهم يصلون لمستوى عالي من التعلم ويعطي وقتا أضسافيا

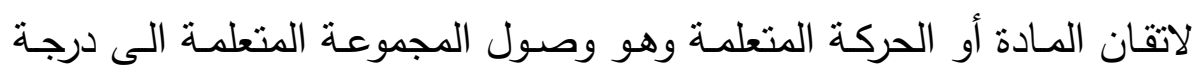

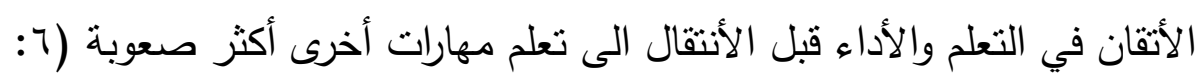
(o)

" مدرس بقسم مناهج وطرق تدريس التربية الرياضية بكلية التربية الرياضية للبنين والبنات جامعة ببورسعبد

مجلة أسيوط لعلوم وفنون التربية الرياضية 
ويشير "الأسمر" (9 . . ب) إلى أن الأساليب التدريسية الحديثة تعد من نتاجات التعلم الحديثة وهي موقف تعليمي تعتمد على طرح الأسئلة أمام الطلبة وتدفعهم للإجابة عليها وجمعها وتبويبها وتفسيرها من حيث الأهمية وباستخدام

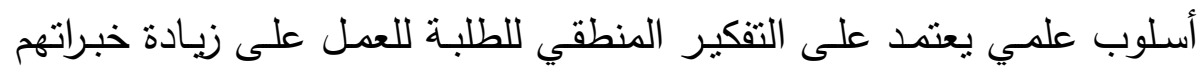

$$
\text { وتقودهم للتوصل إلى المعرفة. ( • (: ب • (1) }
$$

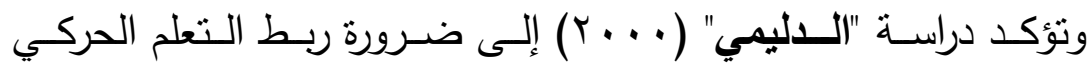

بالأساليب التدريسية الحديثة من جراء تقديم وإعطاء التغذية الراجعة والضرورية عند الأداء وممارسة تعديل الأخطاء وربط متطلبات الأداء للمهارة المراد تعلمها جلهاء وتكرارها حتى يصل المتعلم إلى مرحلة إتقان المهارة وضرورة إعطاء المتعلم

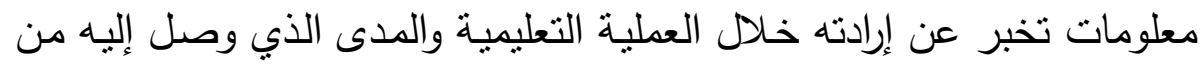
جراء التعلم قبل وأثناء وبعد الأداء للمحافظة على أن يكون التعلم مثثر وفعال.

$(\varepsilon) 1: \mid V)$

ويشير Schmidt" (ד + . r) إلى أن اختيار الأسلوب التدريسي الذي

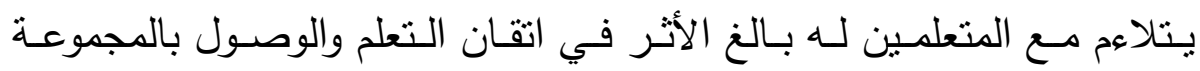
المتعلمـة إلى درجـة الإتقان في التعلم والأداء قبـل الانتقال إلى تعلم مهارات

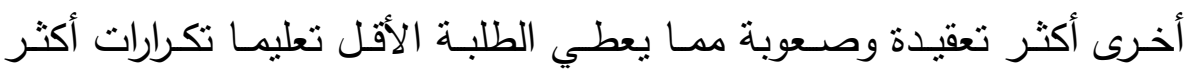
واهتمـام أكثر لغرض الوصـول بـأفراد المجموعـة إلى درجة عاليـة من الإتقان.

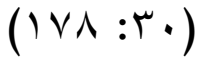

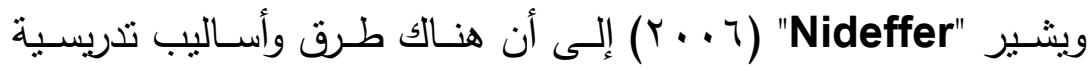
حديثة تستخدم تطوير العملية التعليميـة منها التعلم الاتقاني الذي يؤدي إلى في تطوير مستوى الأداء المهاري في درس التربية الرياضية مما يعزز الاتجاهات

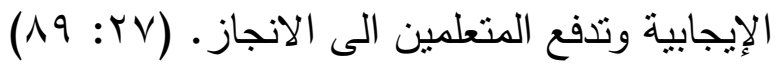

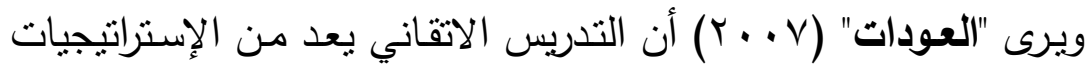

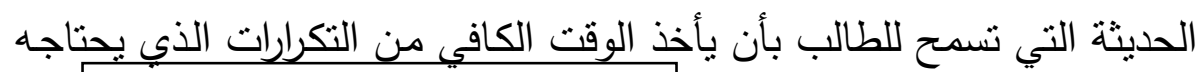
مجلة أسيوط لطوم وفنون التربية الرياضية 
في العملية التعليمية قبل الانتقال إلى تعلم مهارة أخرى أي أن كافة المتعمين

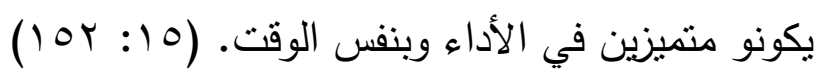

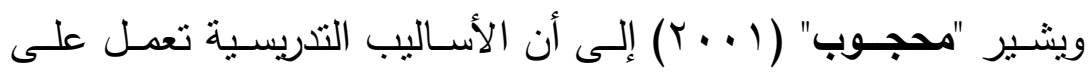

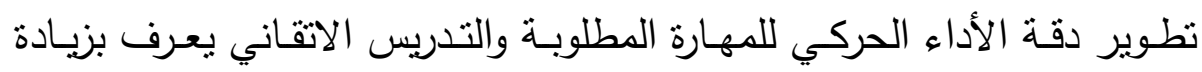

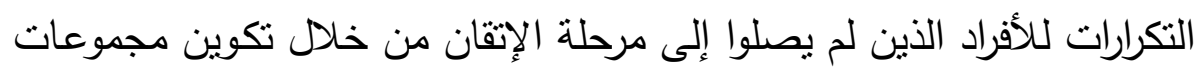

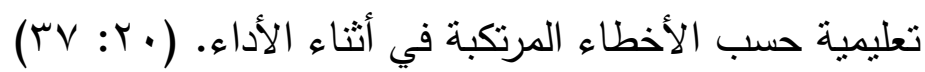

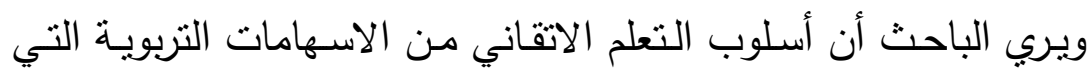

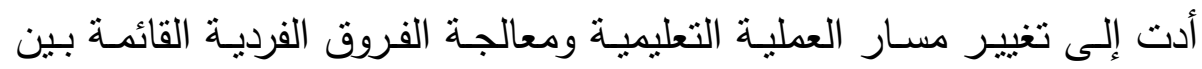
المتعلمين ضمن نطاق الفصل الدراسي النظامي، فأسلوب التعلم الاتقاني يتيح

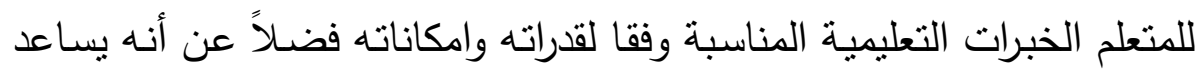

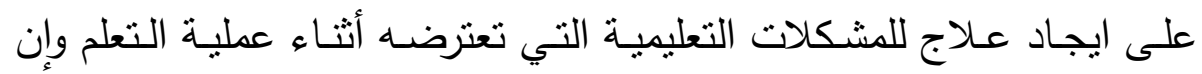

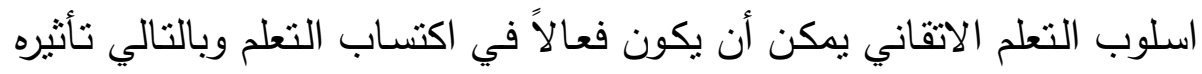

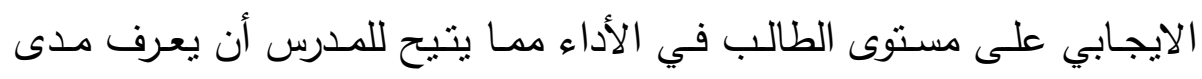
احتفاظهم للمهارة في الذاكرة.

وإن الاسـاليب التقليدية المستخدمة (أسلوب الأوامر) في تعلم المهارات

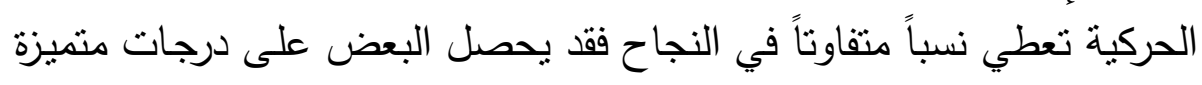

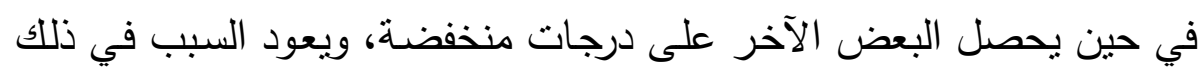

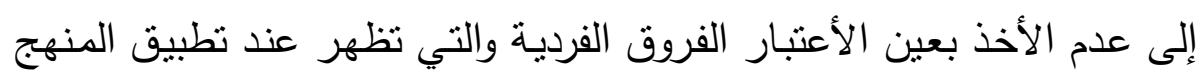

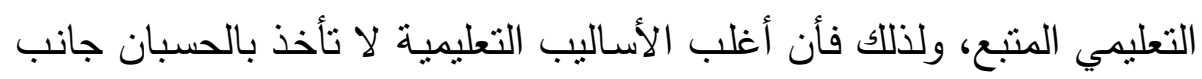

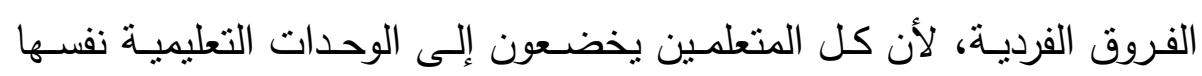

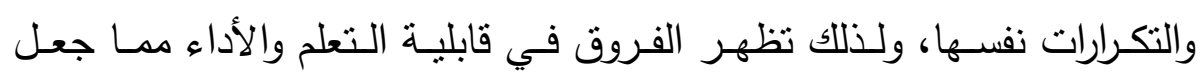

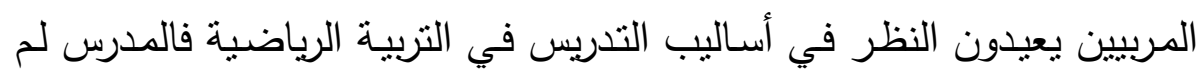

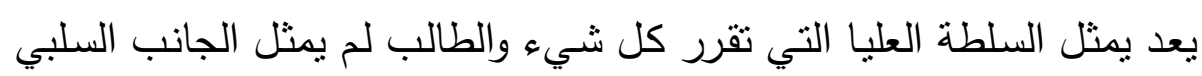

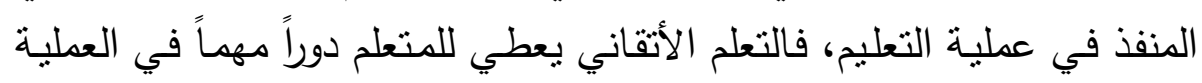
التعليمية. 
ولقد أثتتت الدراسات أن اختيار الإستراتيجية والأسلوب المناسب لتدريس

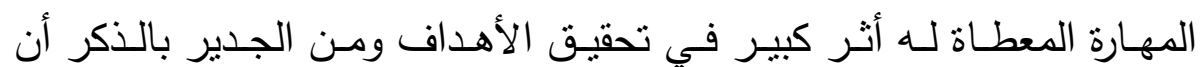
إستراتيجية التدريس الإتقاني تعد من الإستراتيجيات الحديثة التي تساعد الطلبة في الانسجام مـع المادة التعليمية فالطالب ضمن هذه الإستراتيجية غير منلق المعلومات فقط بل مشاركاً وياحثا عن المعلومة بشتى الوسائل الممكنة وهذا ما استدعى الباحث للقيام بهذه الدراسـة والمتمثلة في التعرف علي تأثير استخدام اسلوب التعلم الاتقاني في التعلم والاحتقاظ لبعض المهارات الأساسية بكرة اليد

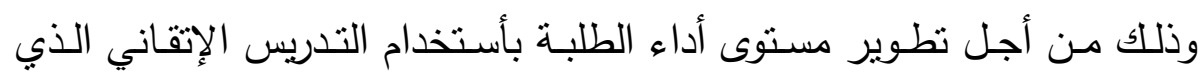
يساعد في تحسين العملية التدريسية حيث أنه من الأساليب التدريسية الحديثة.

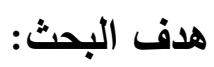

يهدف البحث الى التعرف على تأثير إستخدام أسلوب التعلم الاتقاني في التعلم والاحتفاظ لبعض المهارات الأساسية بكرة البد. فروض البحث: ا- توجـد فروق ذات دلالــة إحصـائية بـين القيـاس القبلي والقيـاس البعـدي

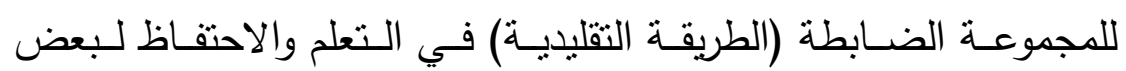
المهارات الأساسية بكرة اليد لصالح القياس البعدي.

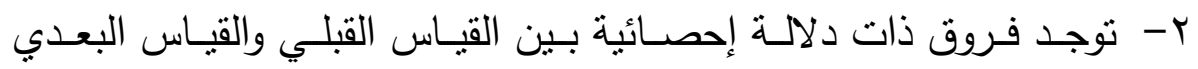
للمجموعة التجربيية (التعلم الاتقاني) في التعلم والاحتفاظ لبعض المهارات الأساسية بكرة اليد لصالح القياس البعدي.

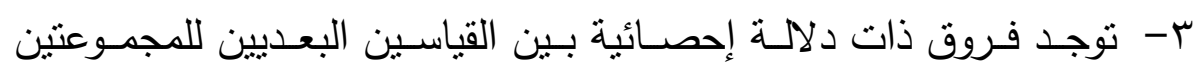

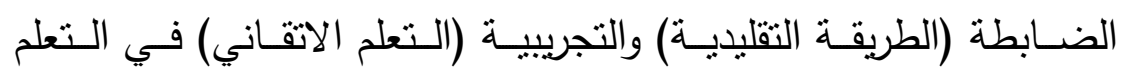
والاحتفاظ لبعض المهارات الأساسية بكرة البد لصـالح القياس البعدي للمجموعة التجربيية. مجلة أسيوط لطوم وفنون التربية الرياضية 


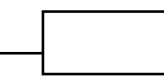

ع- توجد فـروق ذات دلالــة إحصـائية بـين القياسـين البعديين للمجمـوعتين

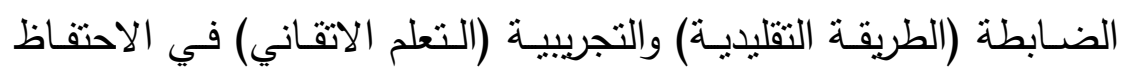

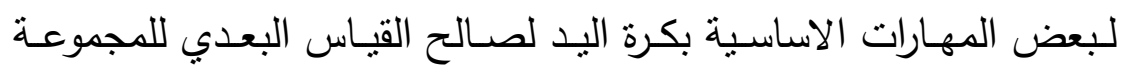
التجريبية.

التعريف ببعض المفاهيم والمصطلحات الواردة في البحث:

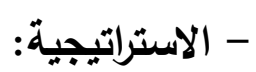
هي عبارة عن وسيلة اتصـال بين المدرس والطالب لتحقيق الأهداف التئية

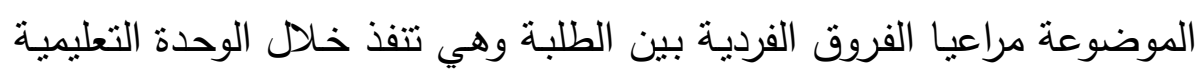

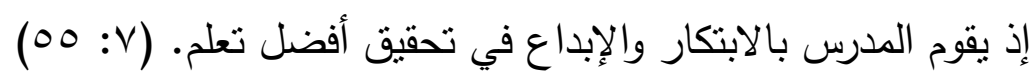

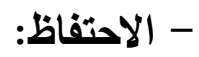

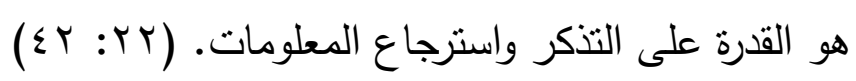

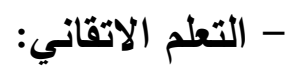
يعرف (1990) التعلم الاتقـاني "بأنسه خيـار جديـ للتعليم

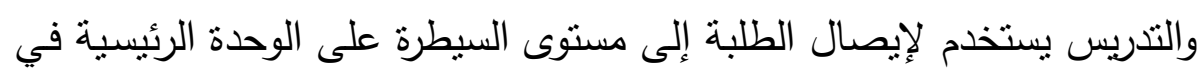

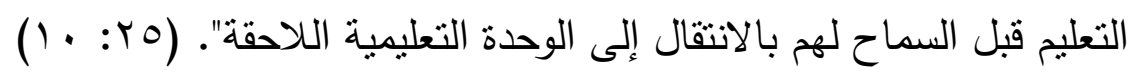

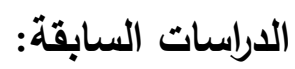

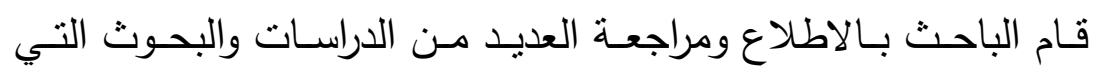

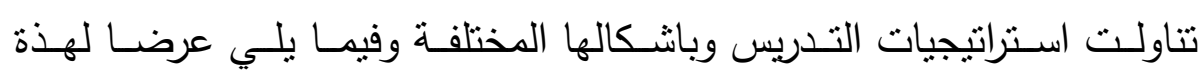
الدراسات مرنبة من الأحدث إلى الأقدام الاراسات العربية:

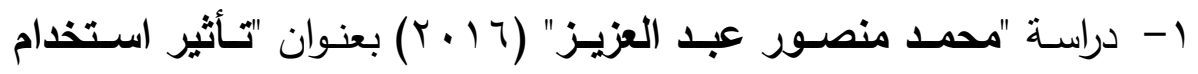

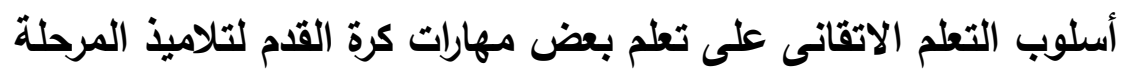

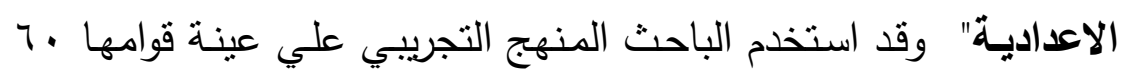

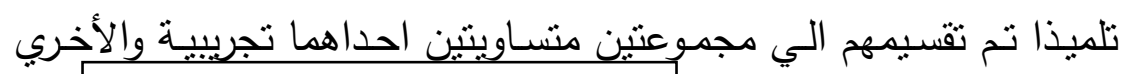
مجلة أسيوط لعوم وفنون التربية الرياضية 
ضـابطة قوام كل منها (·r) تلميذ وكانت أهم النتائج هي وجود فروق

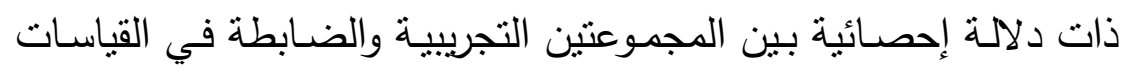

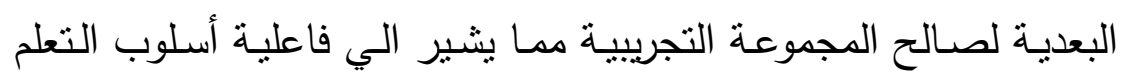
الاتقاني في تعلم بعض مهارات كرة القدم لتلاميذ المرحلة الإعدادية.(ع ( )

ץ- دراسة "ايمـان احمد عبده" (7 1 • ب) بعنوان "تأثير إستخدام إستراتيجيه

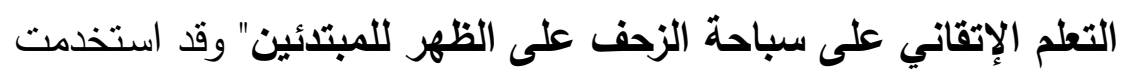

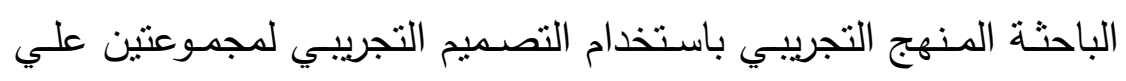
عينة قوامها (Y (Y) مبتدئ وقد تم تقسيمهم الي مجموعتين احداهما تجريبية

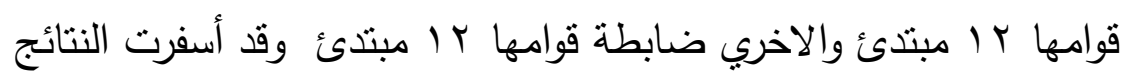

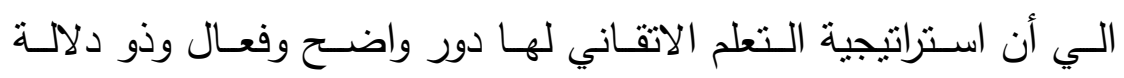

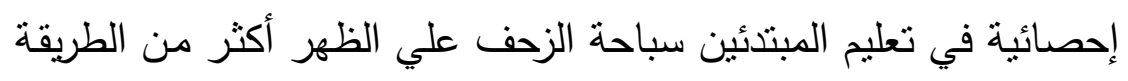

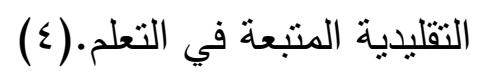

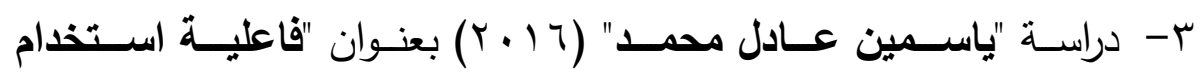

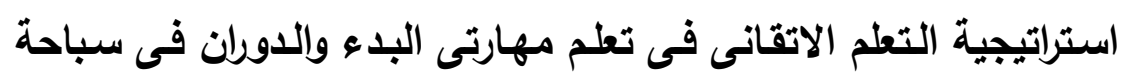

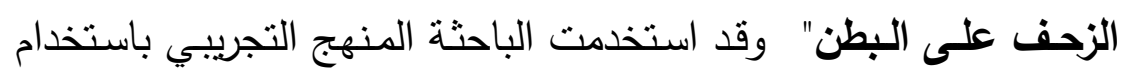

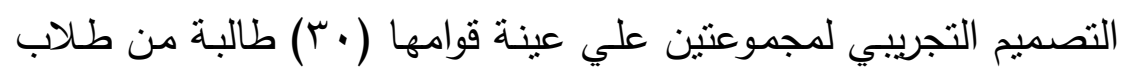

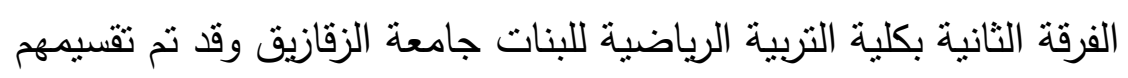

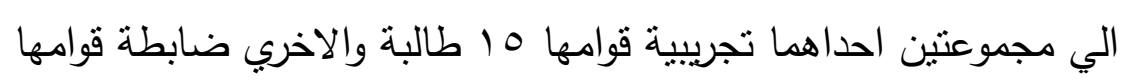

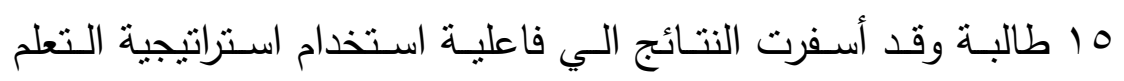

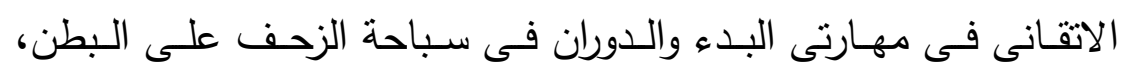

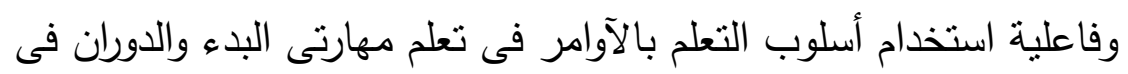

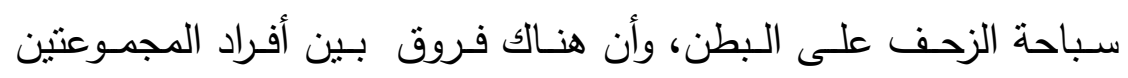

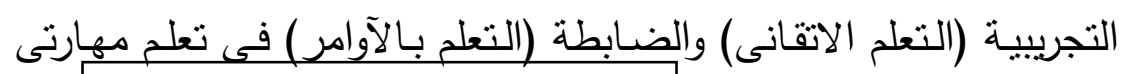
مجلة أسيوط لطوم وفنون التربية الرياضية 
البدـء والدوران فـى سباحة الزحف على البطن لصـالح أفراد المجموعـة

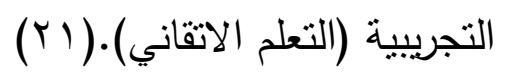

ع - دراسـة "إبراهيم السليمان" (0 1 • ب) هدفت التعرف على "تأثير استخدام الوسـائل التعليميـة في اكتسـاب واحتفـاظ التعلم المهاراتي التمريـر مـن الأعلى والأسفل بالكرة الطائرة" وأيضا التعرف على أفضل وسائل التعلم

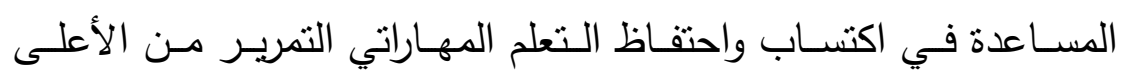
والأسفل بالكرة الطائرة على عينة بلغت ( • ع) طالبا من طلبة السنة الثانية بكليـة التربيـة الرياضـية في جامعـة الأنبـار، واسـتخدم الباحـث المـنهج التجريبي وقسم العينـة إلى مجموعتين ضـابطة وتجريبيـة لكل واحد منها

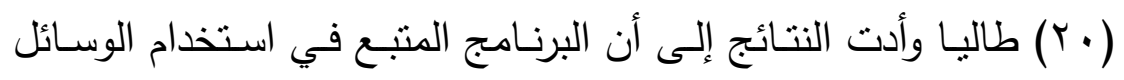

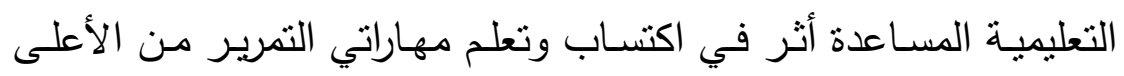

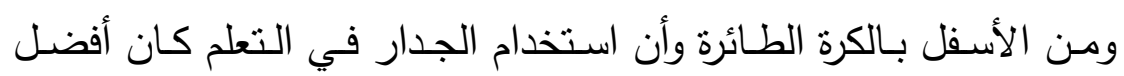

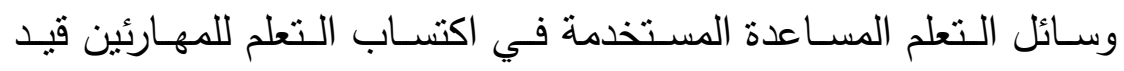

$$
\text { الدراسة يليه التعلم مع الذات ومن ثم التعلم مع الزميل.(1) (1) }
$$

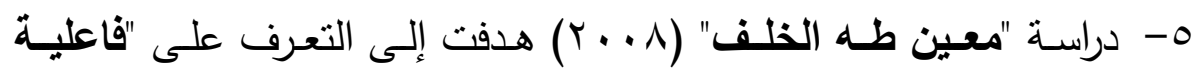
أسلوب التعلم التعاوني والتعلم الاتقاني في تعلم المهارات الأساسية في لعبة تنس الطاولة" واستخدم الباحث المنهج التجريبي على عينة مكونة من ( • () طالبة مقسمين إلى مجموعتين من طلبة كلية التربية الرياضية في الجامعة الأردنية، وتوصلت نتائج الدراسة إلى تفوق المجموعتان اللتان

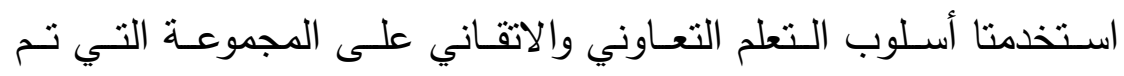
التدريس لها بالطريقـة التقليديـة في بعض المهارات الأساسية الرياضـية

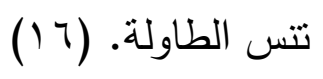

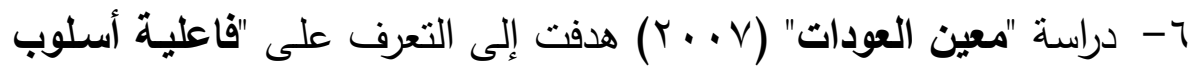
التدريس الاتقاني للمجموعة التجريبية والمقارنة مع المجموعة الضابطة مجلة أسيوط لعلوم وفنون التربية الرياضية 
في تطوير الأداء المهاري في الكرة الطائرة" وأيضا التعرف على الفروقات بين القياسـات القبلية والبعديـة للمجموعتين التجريبية والضـابطة في كرة

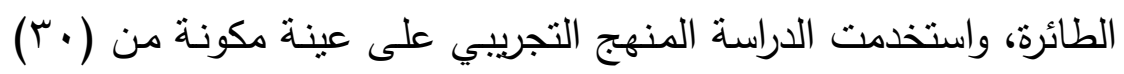

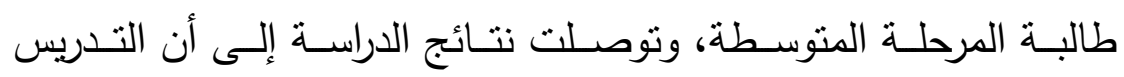
الاتقاني أفضل من الأسلوب التقليدي في تعلم اداء مهارات الكرة الطائرة

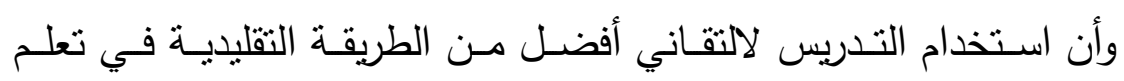

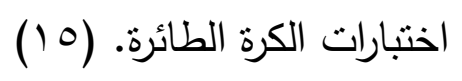

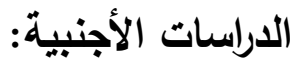

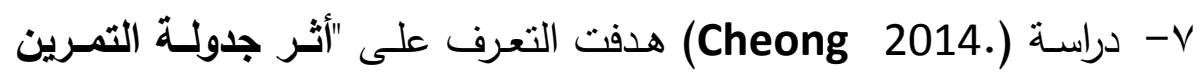

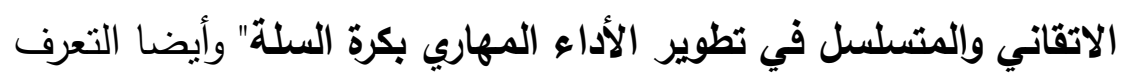

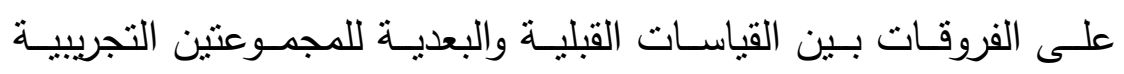

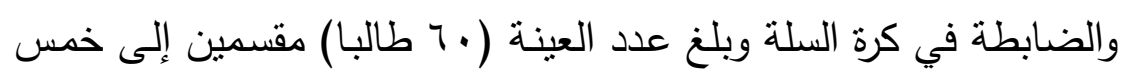

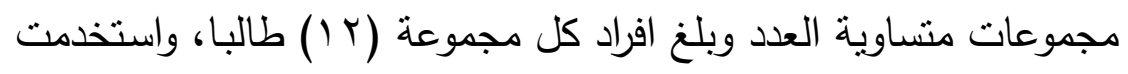

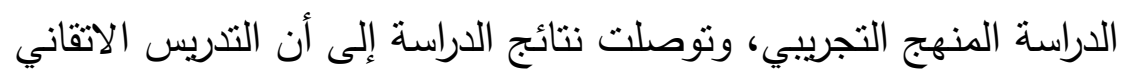

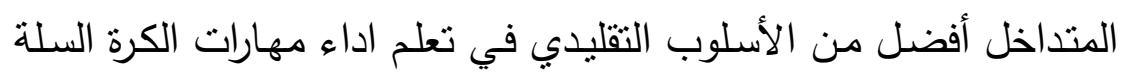

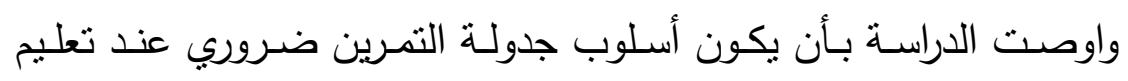

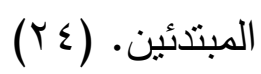

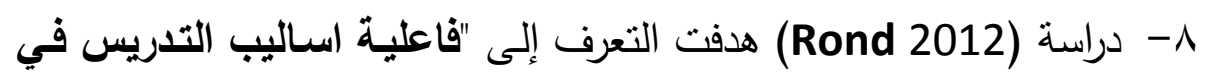

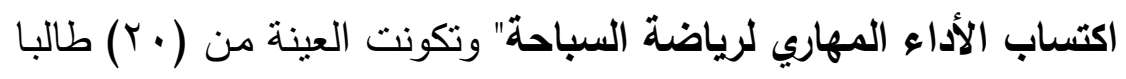

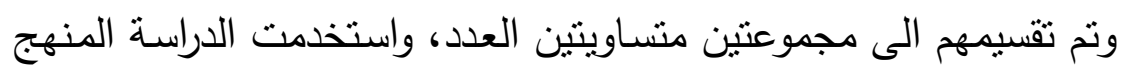

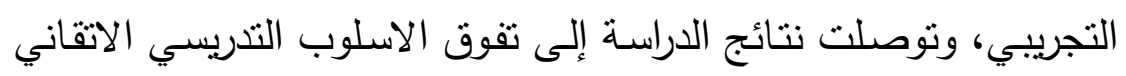

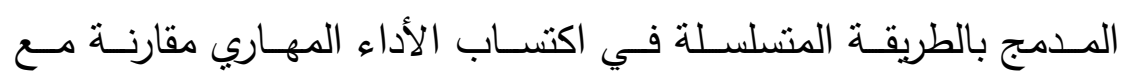
المجموعة الضابطة. (r^)

مجلة أسيوط لعلوم وفنون التربية الرياضية 
خطة وإجراءات البحث: إ:

منهج البحث:

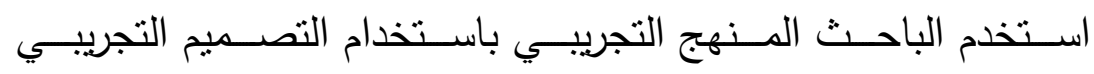

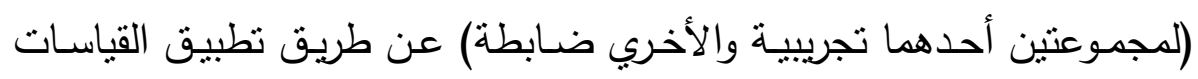

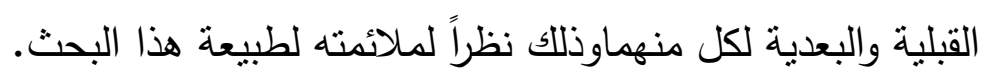

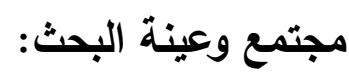

تم اختيارمجتمع البحث بالطريقة العمدية والمتمثل بطلاب الفرقة الدراسية

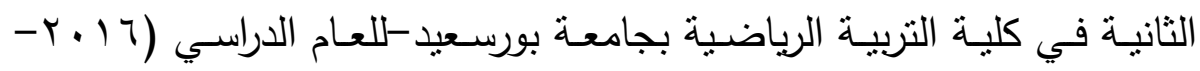

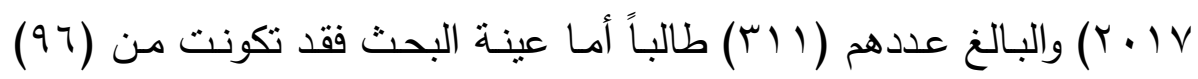
طالباً تم اختيارهم بالطريقة العدية العشوائية، وقد ثم تقسيمهم الى مجموعتين

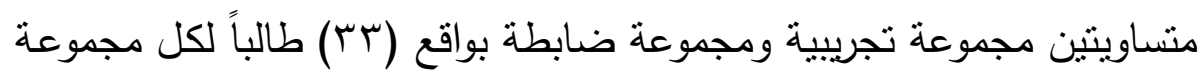
بطريقة القرعة، بعد أن أستبعد الباحث عدداً من الطلاب للأسباب الاتية: 1- الطلاب الباقون للاعادة وعددهم (0) طلاب. r- الطلاب الممارسون وعددهم (V) طلاب. r- طلاب التجربة الاسنطلاعية (• () طلاب. ع - الطلاب المصابون (^) طلاب. وسائل وأدوات جمع البيانات: أ- الأجهزة والأدوات المستخدمة: وانئ

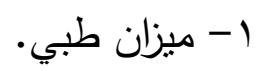

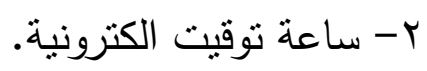
ك- كومبيوتر نوع (DATA SHOW) - (HP) ع - كرة طبية بوزن (r كغم).

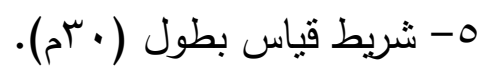
4- كرات يد قانونية. 


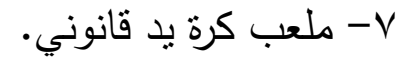

ب- ب - وسائل جمع البيانات:

- المقابلة الثخصية مع ذوي الخبرة والمتخصصين في مجال البحث.

- اختبارات بدنية وحركية

- اختبارات مهارية

ج- القياسات والاختبارات:

- قياس كل من السن والطول والوزن.

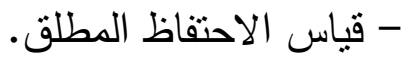

- اختبارات عناصر اللباقة البدنية والحركية المؤثرة على الأداء الفني.

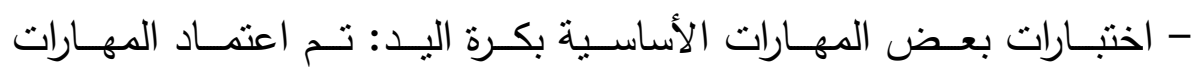

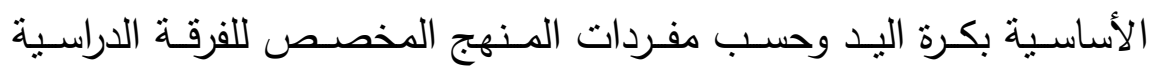

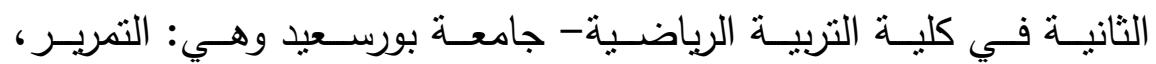

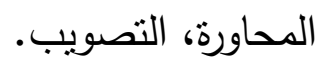

تم تحديد الاختبـارات وفقا للمهارات المؤادة على الطـلاب مـن خـلال العـرض على السـادة الخبـراء والمختصـين بكرة اليـد الملحق (Y) وقد اختـار الباحث الاختبارات التي حققت (\%)\% فأكثر من اراء السـادة الخبراء وهذه الاختبارات هي: - الختات

1- اختبار التوافق وسرعة التمرير لمدة • ب ثانية. r- اختبار المحاورة المتعرجة (بتغيير الأتجاه). r- اختبار التصويب بالوثب عاليا.

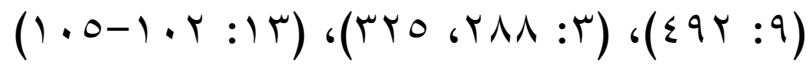

- صدق وثبات الاختبارات البلنية والمهارية قيد البحث اعتمد الباحث في صدق وثبات الاختبارات البدنية والمهارية قيد البحث على الأبحاث التي أجربت في مجال كرة اليد والتي استخدمت نفس الاختبارات

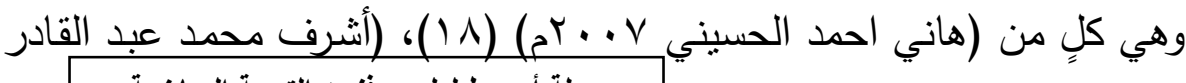
مجلة أسيوط لعلوم وفنون التربية الرياضية 


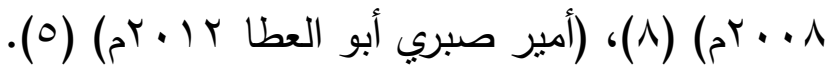

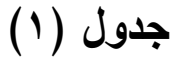

صدق وثبات الاختبارات البذنية والمهارية قيد البحث

\begin{tabular}{|c|c|c|c|c|c|}
\hline \multicolumn{2}{|c|}{ معامل الثبات } & \multicolumn{2}{|c|}{ معامل الصدق } & \multirow{2}{*}{ الاختبار } & \multirow{2}{*}{ م } \\
\hline الي & 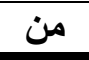 & 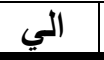 & 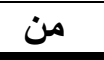 & & \\
\hline \multicolumn{6}{|c|}{ الاختبارات البينية قيد البحث } \\
\hline. .19 & $\cdot .11$ &. .97 & $.9 \varepsilon$ & السرعة الانتقالية & 1 \\
\hline. .19 & $\because \vee \leqslant$ & .911 &..$\wedge 7$ & القوة الانفجارية للأطراف العليا & r \\
\hline. .97 &. .94 &. .91 &..$\wedge \mathrm{V}$ & الرشناقة & $r$ \\
\hline \multicolumn{6}{|c|}{ الاختبارات المهارية قيد البحث } \\
\hline..$\wedge 1$ &..$\wedge r$ &. .19 & $.1 \times 0$ & اختبار التوافق وسرعة التمرير لمدة • ثانية & 1 \\
\hline. .97 &. $.7 \varepsilon$ & $.9 r$ &. .09 & اختبار المحاورة المتعرجة & $r$ \\
\hline.$\wedge$ &. .71 & .94 &. .07 & اختبار التصويب بالوثب عاليا & $r$ \\
\hline
\end{tabular}

يتضح من جدول ( (1) أن جميع قيم معامل الصدق للاختبارات البدنية

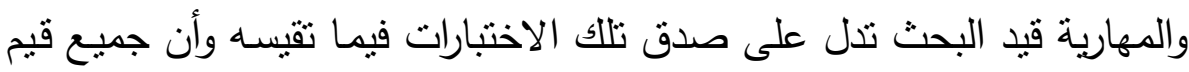
معامل الثبات تدل على ثبات تلألك الاختبارات. تجانس مجموعتي البحث:

قام الباحث بإجراء التجانس والتكافؤ بين مجموعتي البحث في المتغيرات

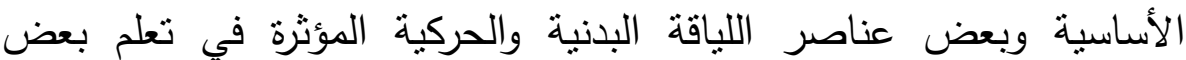
المهارات الاساسية بكرة اليد والتي اتفق عليها المختصون وكالآتي:

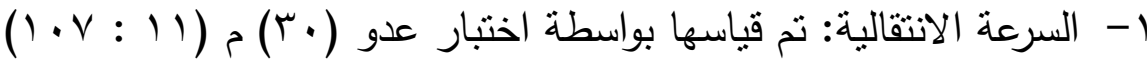

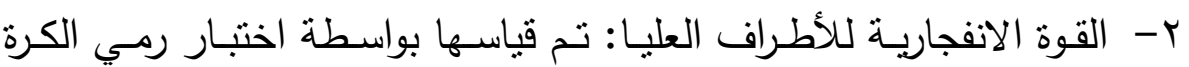

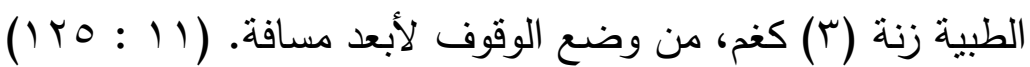

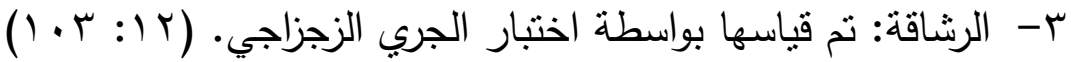

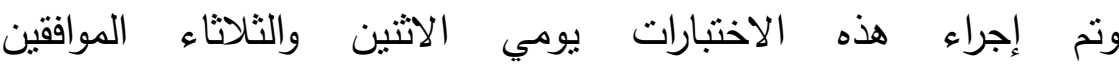

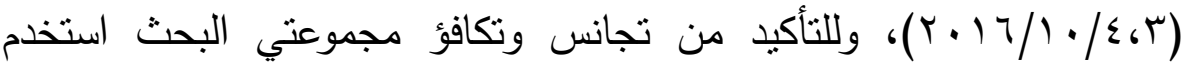
الباحث اختبار (ت) للعينات المتساوية والجدول (r) يبين ذلك. 


\section{جدول (Y)}

الوسط الحسابي والانحراف المعياري وقيمة (ت) بين المجموعتين التجريبية والضابطة في متغيرات (السن، الطول، الوزن) ويعض وفيمة عناصر التين اللياقة البذنية (

\begin{tabular}{|c|c|c|c|c|c|c|c|}
\hline \multicolumn{3}{|c|}{ الضابطة } & \multicolumn{3}{|c|}{ التجريبية } & \multirow{2}{*}{ القياس } & \multirow{2}{*}{ المتغيرات المات الاحصائية } \\
\hline الالتواء معامل & $\varepsilon \pm$ & 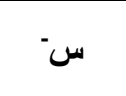 & الالتواء & $\varepsilon \pm$ & س" & & \\
\hline .01 & $1 \varepsilon, \lambda r$ & rTV & $\cdot \leq \varepsilon-$ & $17, \cdot 1$ & rrq & شـهر & 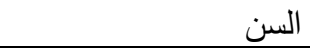 \\
\hline $7 . \wedge \wedge$ & $\varepsilon, \wedge \Gamma$ & $1 V \varepsilon$ & .9 & $\varepsilon, \varepsilon$ & 187 & سم & الطول \\
\hline A.r. & $0, Y M$. & 77 &.$V$. & $\varepsilon, \vee \wedge 0$ & 70 & كجم & الوزن \\
\hline • & $\cdot, r q \leq$ & $\varepsilon, \varepsilon \varepsilon 1$ & $.0 V_{-}$ & $\cdot, r \leq$. & $\varepsilon, \varepsilon \mu_{0}$ & ثانية & السرعة الانتقالية \\
\hline .11 & $\cdot, V \leqslant 1$ & $V, 1 \leq$ &.$\mu r$ & $\cdot, V \cdot V$ & $\vee, 1 \wedge$ & منز & القوة الانفجارية للأطراف العليا \\
\hline$\cdot r \cdot$ & • & $V, T \leqslant$ & $\cdot r r_{-}$ & מצT, & $V, Y V$ & ثانية & الرشاقة \\
\hline$\cdot V \cdot-$ & l.Av. & $11.1 \ldots$ &. $.4 q$ & 1.97. & $1 \wedge .0 \%$. & العدد العد & 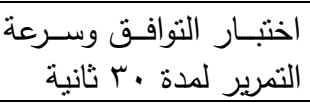 \\
\hline$\because \wedge \mathrm{V}$ & .90 & 11.rT. & .17 & $\cdot . \wedge \leq 7$ & $1 . .99$. & ثانية & اختبار المحاورة المتعرجة \\
\hline $.00_{-}$ & $.2 \times 11$ & l.Ar. & $\cdot \wedge 9-$ &.$\vee \wedge \varepsilon$ & ו. & درجة & عاليا \\
\hline
\end{tabular}

يتضح من الجدول (Y) أن قيم معاملات الالتواء للمجموعتين الضابطة والتجريبية في المتغيرات الأساسية والاختبارات البدنية والمهارية قيد البحث قد انحصرت ما بين (- r إلى + r ) مما بدل على تجانس أفراد المجموعتين الضابطة والتجريبية في تلك الاختبارات. التكافؤ في الاختبارات المهارية: قام الباحث باجراء عملية التكافؤ بين مجموعتي البحث في يوم الاثثين

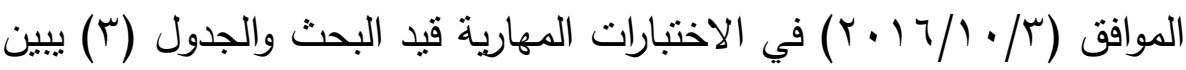
ذلك.

\section{جدول (r)}

الوسط الحسابي والانحراف المعياري وقيمة (ت) بين المجموعتين التجريبية

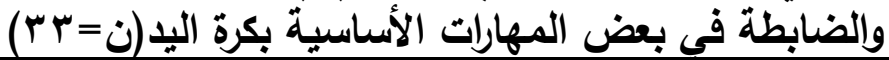




\begin{tabular}{|c|c|c|c|c|c|c|c|}
\hline الاحصائية & المحسوبة & $\varepsilon \pm$ & س - & $\varepsilon \pm$ & س - & القياس & الالمتغيائية \\
\hline غعنوير & .914 & $1 . \wedge V$. & $11.1 \ldots$ & 1.97. & 11.0r. & العدد & 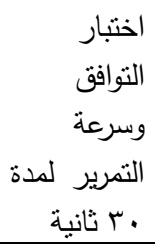 \\
\hline غعنوي & $1 . . \wedge \varepsilon$ & .90. & . I. ו & $. \wedge \leq 7$ & $1 . .99$. & ثانية & المتلبار \\
\hline غعنوير & $.0 Y 7$ &.$v \backslash 1$ & I.人. &.$\vee \wedge \varepsilon$ & משV. I & درجة & التصويب التبار \\
\hline
\end{tabular}

يتضح من الجدول (r) عدم وجود فروق ذات دلالة احصائية بين طلاب مجموعتي البحث في المتغيرات المهارية قيد البحث حيث أن قيمة (ت) المحسوبة أقل من قيمة (ت) الجدولية عند مستوي دلالة (0 . . ) مما يدل على فئي تجانس وتكافؤ أفراد العينة في تلك المتغيرات.

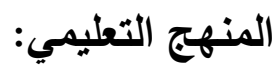
استتد الباحث على المراجع العلمية في اعداد المنهج التعليمي على وفق أسلوب (التعلم الإتقاني) ومن ثم ثتّ عرضه على المختصين المشار اليهم سابقاً في مجال كرة البد والتعلم الحركي وطرق التدريس وذلك للتأكد من مدى الإنى صلاحيته وأبداء آرائهم وملاحظاتهم في المنهج من حيث التأكد من صلاحية ولنية تطبيق المنهج باسلوب (التعلم الاتقاني) والتقسيم الزمني لأجراء الوحدة

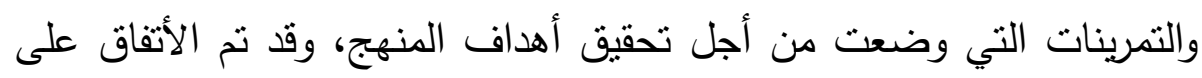
صلاحية البرامج التعليمية من قبل كافة المختصين بعد أن تم الأخذ بكافة الملاحظات العلمية التي أبدوها والملحق (1) يوضح نموذج لوحدة نعليمية بأسلوب (التعلم الاتقاني) وتضمن المنهج التعليمي على (T آ) وحدة تعليمية لكلتا مجموعتي البحث (^) وحدة تعليمية للمجموعة التجربيية (إسلوب التعلم مجلة أسيوط لعلوم وفنون التربية الرياضية 
الأتقاني)، و (^) وحدة تعليمية للمجموعة الضابطة (الأسلوب المتبع) وقد

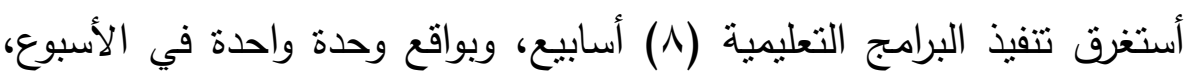
وكان زمن الوحدة التعليمية للمجموعنين (•9) دقيقة.

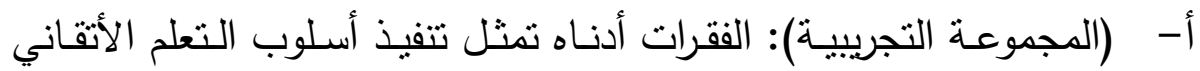

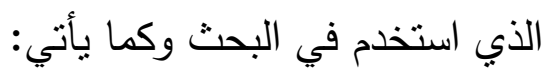

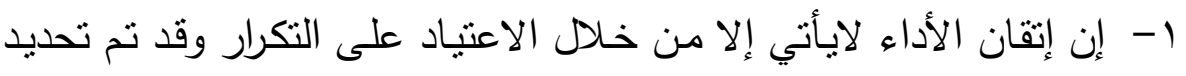

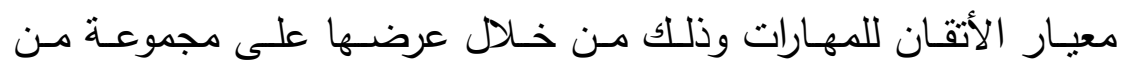

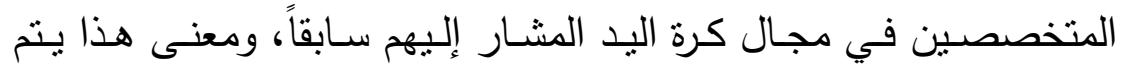

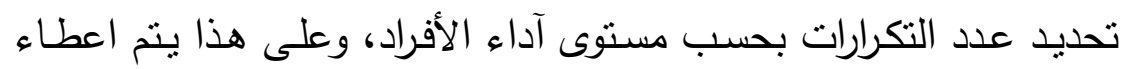

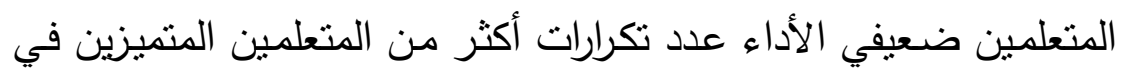

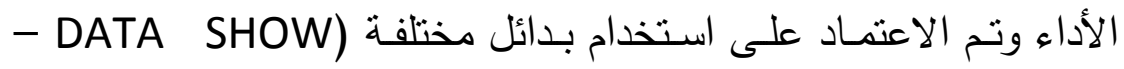
النشرات-الكتيب) في التكرارات لتجنب الملل وزيادة التثويق.

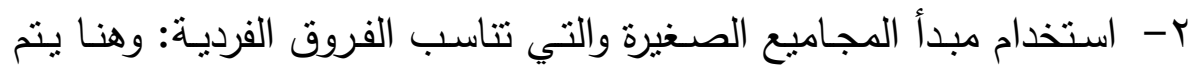

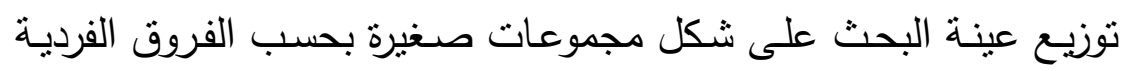

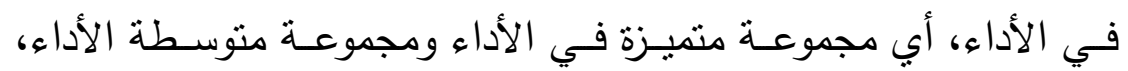

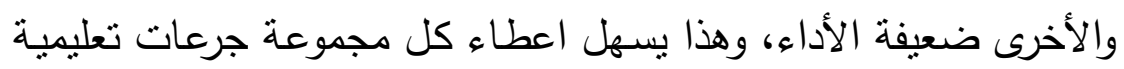
تتناسب مع المستوى الذي هي عليه. r- إستخدام مبدأ اشراك الطلبة المتنيزين في التعلم: انطلاقاً من مبدأ الفروق الفيه

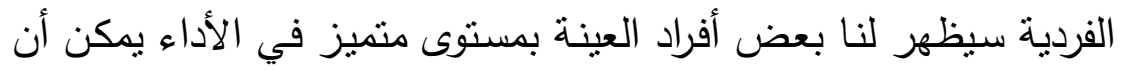

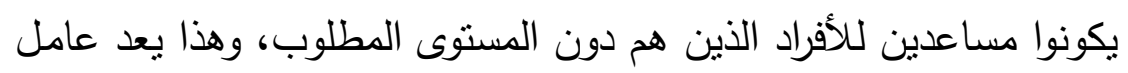

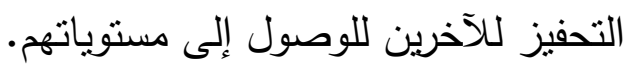

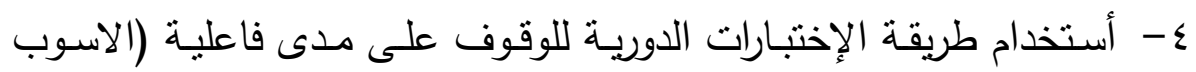

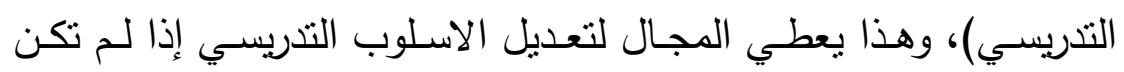

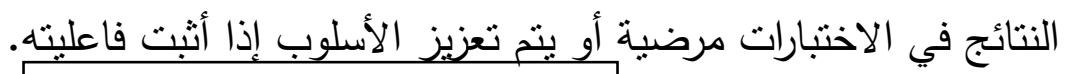
مجلة أسيوط لطلوم وفنون التربية الرياضية 
ب- (المجموعة الضابطة): نففت الأسلوب التقليدي.

التجربة الاستطلاعية:

قام الباحث بإجراء التجربة الاستطلاعية على عينة من (· (1) طلاب الابنة

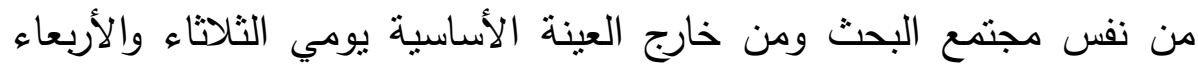

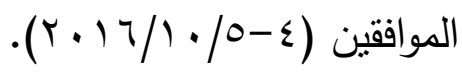

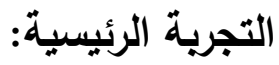

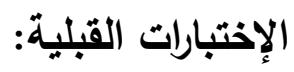

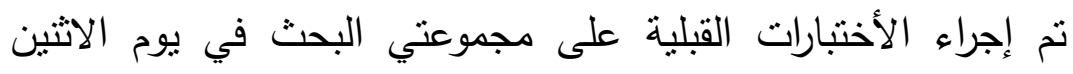

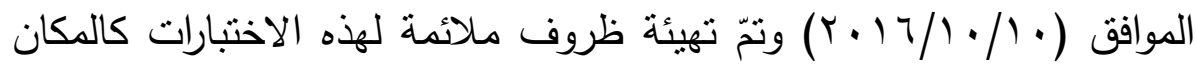

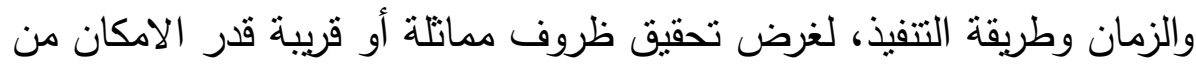

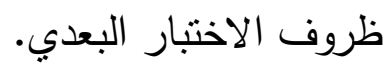

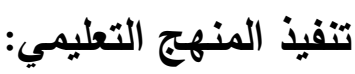

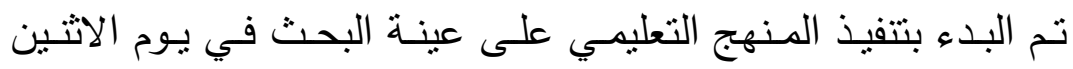

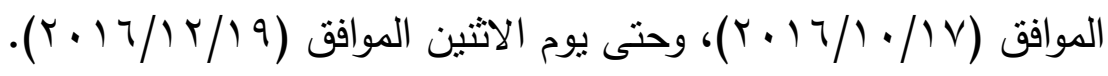

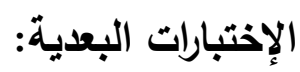

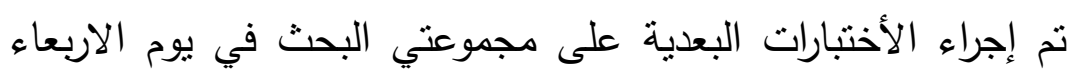

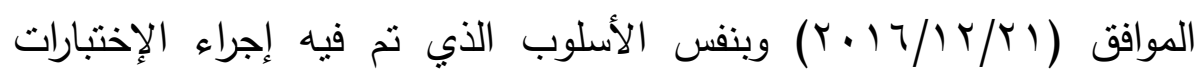
القبلية.

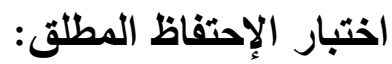

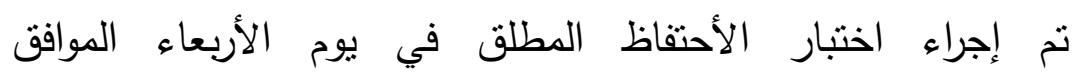
(Y. IV/T/\&) للاحتفاظ والقياس بعدها بنفس اختبارات بعض المغ المهارات الأساسية بكرة اليد.

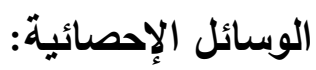
استخدم الباحث الحقيبة الاحصائية (spss) لاستخراج النتائج مستعيناً

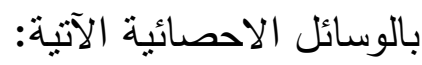
مجلة أسيوط لعوم وفنون التربية الرياضية 


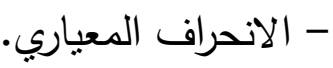

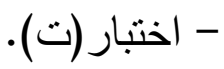

- الوسط الحسابي.

- معامل الالتواء.

- النسبة المئوية.

عرض وتحليل النتائج ومناقشتها:

عرض نتائج الفرض الأول:

\section{جدول (๕)}

الوسط الحسابي والانحراف المعياري وقيمة (ت) للقياسات القبلية والبعدية

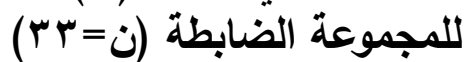

\begin{tabular}{|c|c|c|c|c|c|c|}
\hline \multirow{2}{*}{ مستوي } & \multirow{2}{*}{ قيمة(ت) } & \multicolumn{2}{|c|}{ القياس البعدي } & \multicolumn{2}{|c|}{ القياس القبلي } & \multirow{2}{*}{ الاختبارات } \\
\hline & & $\varepsilon \pm$ & سَ & $\varepsilon \pm$ & سَ & \\
\hline دالة & Q.YI. & $r . . . \Lambda$ & 19.人T. & $1 . \wedge V$. & $1 \wedge .1 \ldots$ & التمبرار التوافق وسرعة لمدانية \\
\hline دالة & V.VII & $.1 \wedge$ & $1.9 \leq$. & .90 . & . מז.11 & المتبرجة \\
\hline دالة & $0 . . V Y$ &..$\vee V I$ & $1.9 \varepsilon$. &.$v 11$ & I.AT. & بالوثبب عاليا \\
\hline
\end{tabular}

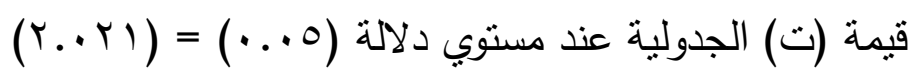

يتضح من الجدول (ع) أن قيمة (ت) المحسوبة للاختبارات قيد البجث

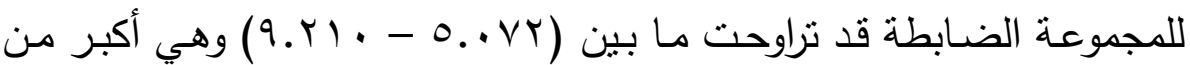
قيمتها الجدوليـة عند مستوي دلالـة (0 . . ) مما يشير الي وجود فروق دالـة احصائيا لصالح القياس البعدي. 


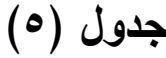

الوسط الحسابي والانحراف المعياري وقيمة (ت) للقياسات

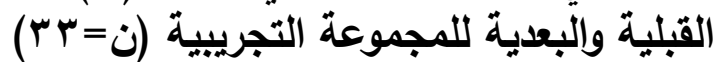

\begin{tabular}{c|c|c|c|c|c|c}
\hline \hline \\
\hline
\end{tabular}

يتضح من الجدول (0) أن قيمة (ت) المحسوبة للاختبارات قيد البحث

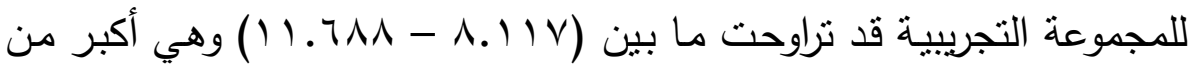
قيمتها الجدولية عند مستوي دلالـة (0 . . ) مما يشير الي وجود فروق دالة احصائيا لصالح القياس البعدي. عرض نتائج الفرض الثالث:

\section{جدول (7) (7)}

الوسط الحسابي والانحراف المعياري وفيمة (ت) (ت) في الاختبارات البعدية

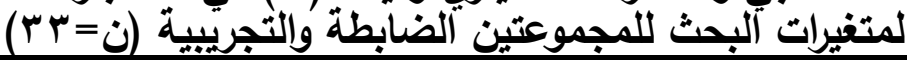

\begin{tabular}{|c|c|c|c|c|c|c|}
\hline \multirow{2}{*}{ مستوي الالالة } & \multirow{2}{*}{ قيمة(ت) } & \multicolumn{2}{|c|}{ المجموعة التجريبية } & \multicolumn{2}{|c|}{ المجمو عة الضابطة } & \multirow{2}{*}{ 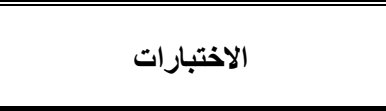 } \\
\hline & & $\varepsilon \pm$ & سن & $\varepsilon \pm$ & سن & \\
\hline دالة & $\varepsilon .+1 T$ & 1.99. & r. Tr. & $r \ldots \lambda$ & 19.人T. & لمدة ابتار التوافت وسرعة التمريز \\
\hline 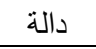 & $0 . \wedge 91$ & $1.1 \cdot 1$ & Q.VT. & $\because 1 \wedge$ & $1.9 \leq$ & اختبار المحاورة المتعرجة \\
\hline 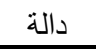 & r... & $\because \vee 7$ & r.07. &..$\vee \vee 1$ & $1.9 \leq$. & اختبار التصويب بالوثب عاليا \\
\hline
\end{tabular}

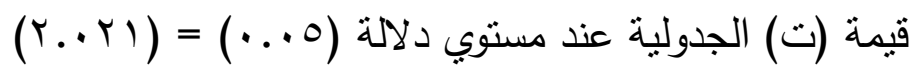

يتضح من الجدول (T) أن قيمة (ت) المحسوبة للاختبارات قيد البحث للمجمـوعتين الضـابطة التجريبيـة في القياسـات البعديـة قد تراوحـت مـا بـين 


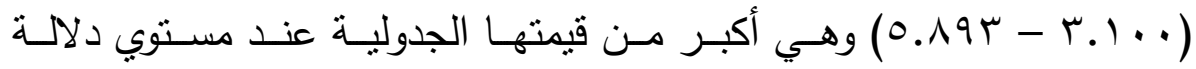

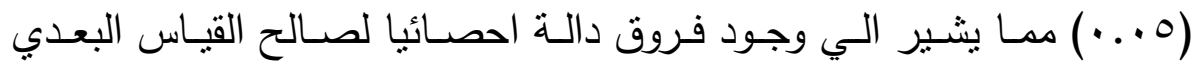
للمجموعة التجريبية.

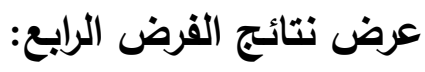

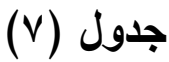

متوسطات الاختبارات البعدية والانحرافات المعيارية واختبار الاحتفاظ والنسبة النجات المئوية للاحتفاظ للمجموعتين التجريبية والضابطة في المباتية والمهارات قيد الاراسة $(\mu r=0)$

\begin{tabular}{|c|c|c|c|c|c|c|}
\hline \multirow{2}{*}{ نسبة } & \multicolumn{2}{|c|}{ اختبار الاحتفاظ } & \multicolumn{2}{|c|}{ القياس البعدي } & \multirow{2}{*}{ المهارات } & \multirow{2}{*}{ المجموعات } \\
\hline & $\varepsilon$ & 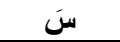 & $\varepsilon$ & سََ & & \\
\hline$\% 7 . .1{ }^{2}$ & r...rT & 11.940 & r... & 19.八r. & التمرير لمدة ابثانية وسرعة & \multirow{3}{*}{ الضابطة المجوعة } \\
\hline$\% \vee 1.0 V Y$ & .190 & V.ヘr. & .11 . & $1 . .9 \leq$ & اختبار المحاورة المتعرجة & \\
\hline$\% 01.7 \leq 9$ & $\cdot . \wedge \cdot 1$ & $1 \ldots r$ &..$\vee V 1$ & $1.9 \varepsilon$. & اختبار التصويب بالوثب عاليا & \\
\hline$\% 97 . \Sigma 9 \wedge$ & r... Ir & 11.170 & 1.99. & r & التمرير لمدة الت ثانية وسرعة & \multirow{3}{*}{ التجريبية } \\
\hline$\%$ qr..rт & I.rT. & $1.9 \leq 0$ & $1.1 \cdot r$ & q.VY. & اختبار المحاورة المتعرجة & \\
\hline$\% \wedge V . r \leq 0$ & $\ldots \vee 91$ & t.M &.$\vee \vee 4$. & r.07. & اختبار التصويب بالوثب عاليا & \\
\hline
\end{tabular}

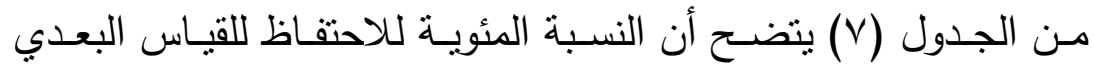

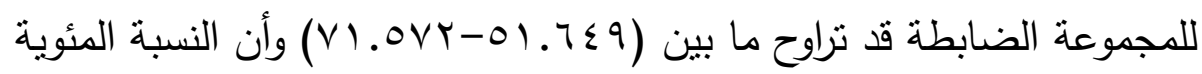

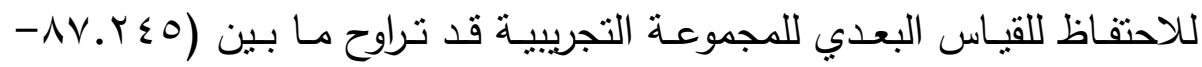

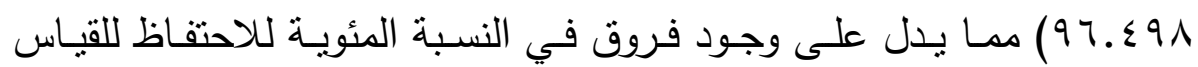
البعدي للمجموعة التجريبية في الاختبارات قيد البحث. مناقثة النتائج

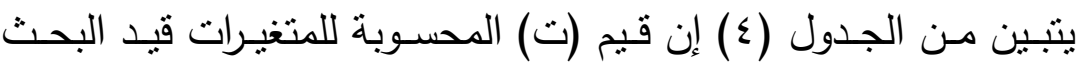

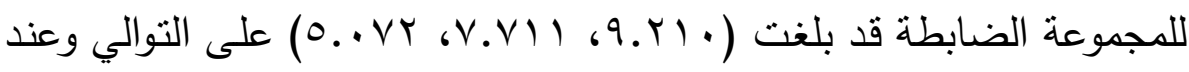

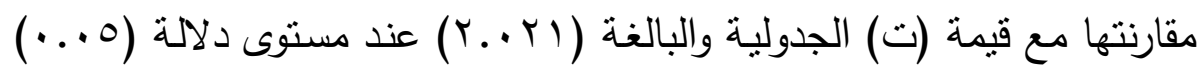
مجلة أسيوط لطوم وفنون التربية الرياضية 
فقد تبين إن قيم (ت) المحسوبة أكبر من الجدولية وهذا يدل على وجود فروق دالة إحصائيا ولصالح الاختبار البعدي للمجموعة الضابطة.

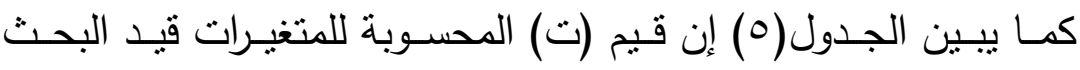

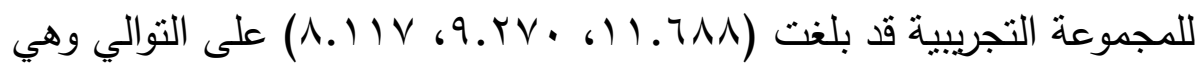

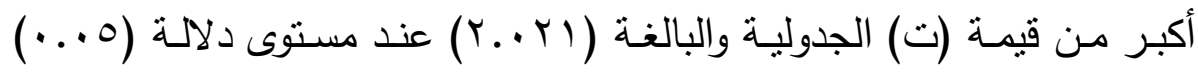

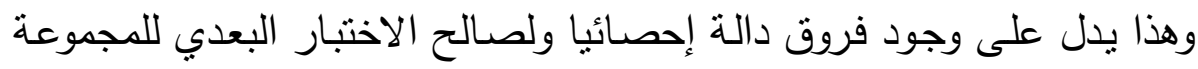
التجريبية.

ويعزو الباحث هذه الفروق للمجموعتين التجريبية والضـابطة على حد

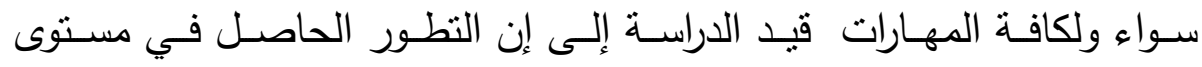
المتعلمين في المجموعنين التجريبية والضابطة على حد سواء رغم الاختلاف

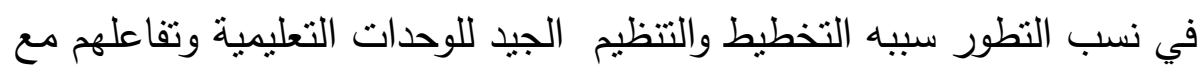

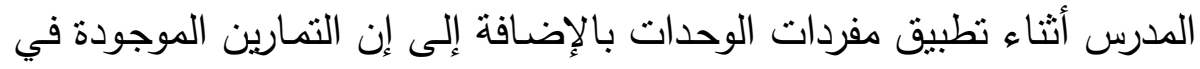

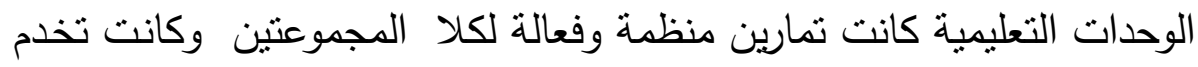

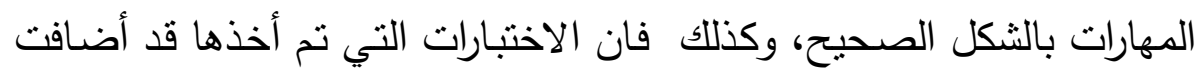

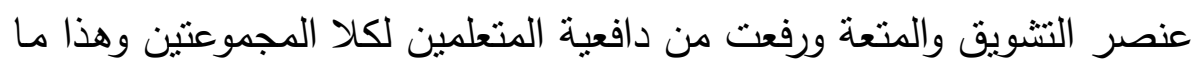

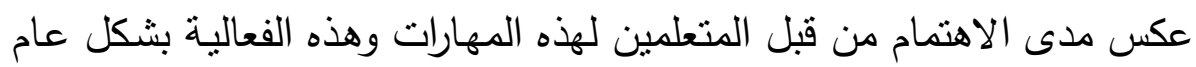

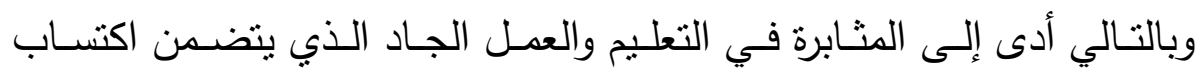

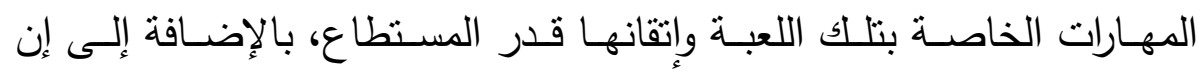

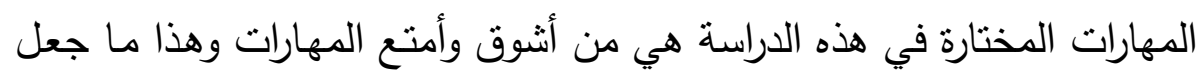

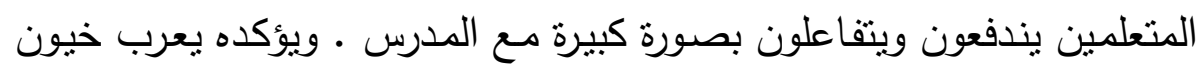

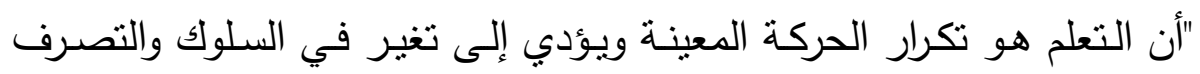

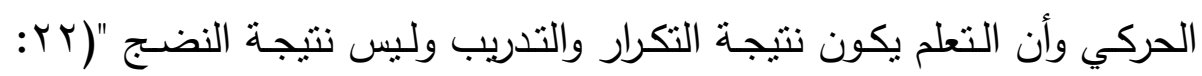


كما يعزو الباحث ظهور فروق دالة احصائيا بين القياس القبلي والبعدي

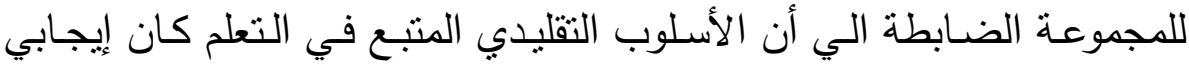

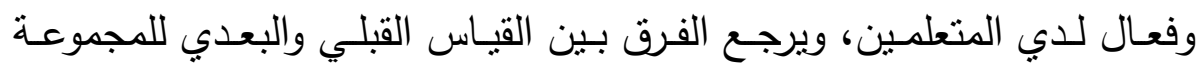

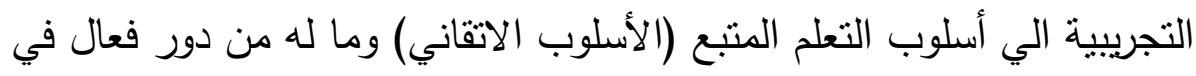

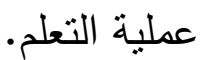

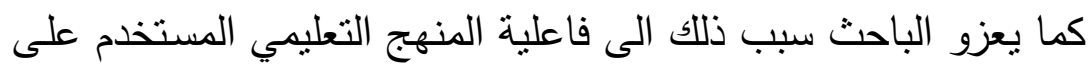
وفق اسلوب التعلم الاتقاني والاسلوب المتبع، إذ إن لطرائف التدريس وأساليبه

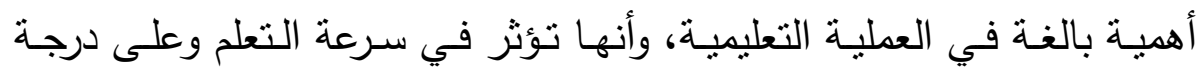

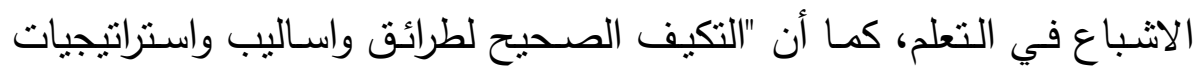

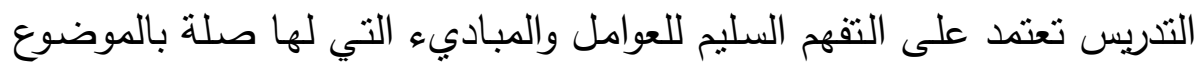
لكي تتبت أثرها وقيمتها في مواقف تعليمية معينة".

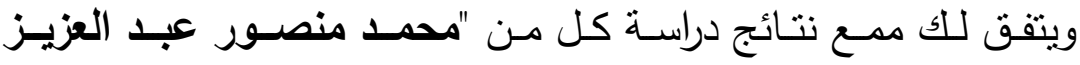

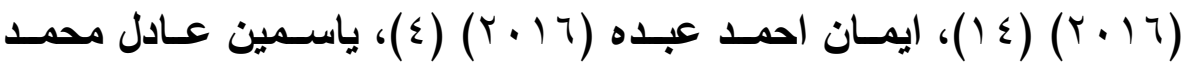

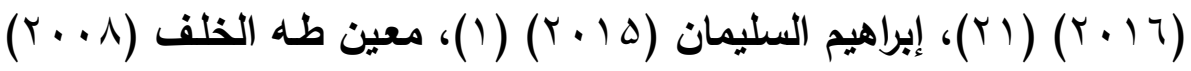

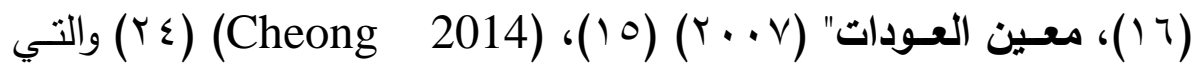

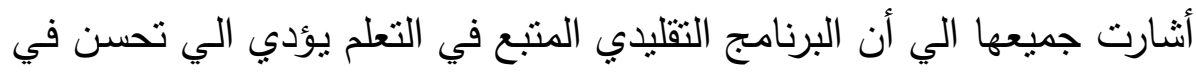

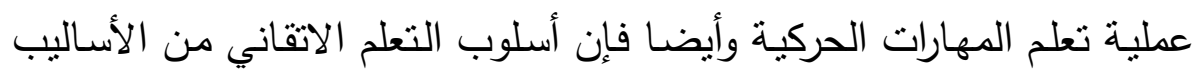

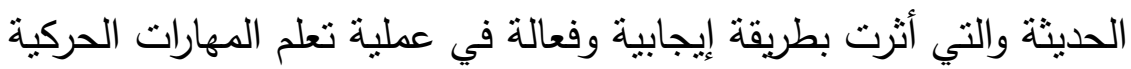

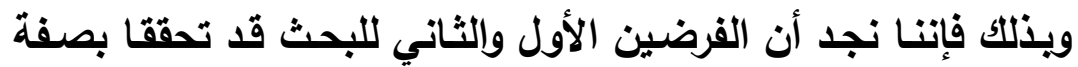
كلية وهم ينصان علي: - - توجد فروق ذات دلالــة إحصـائية بـين القيـاس القبلـي والقيـاس البعدي

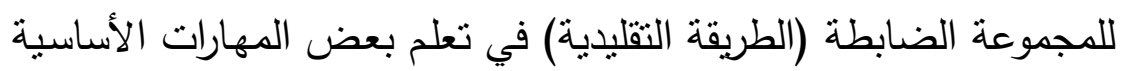
بكرة اليد لصالح القياس البعدي. 
- - توجـد فروق ذات دلالـة إحصـائية بـين القيـاس القبلـي والقيـاس البعـي للمجموعة التجريبية (التعلم الاتقاني) في تعلم بعض المهارات الأساسية بكرة اليد لصالح القياس البعدي. كما بيين الجدول(7) أن هناك فروقاً دالة إحصائياً للاختبارات البعدية بين المجمـوعتين الضــابطة والتجربيــة في المهـارات قيـد البحـث ولصـالح نتـائج

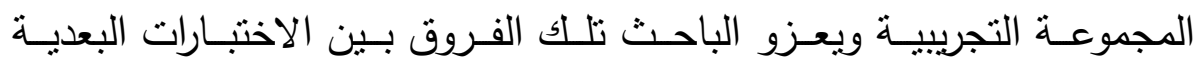
للمجمـوعتين التجريبيـة والضــابطة ولصــالح التجريبيـة إلـى اسـتخدام عينـة المجموعة التجريبية لأسلوب التعلم الاتقاني وهذا المنهج يرتكز على تسـيل وهيل المفردات من السهل إلى الصعب وعدم الانتقال من تعلم مهارة إلى أخرى إلا لإنى بعد أن يتم إتقان المهارة السابقة وترتكز على المعلومات التي تصل إلى المتعلم عن طريق الثرح والتوضيح أي إعطاء المعلومات المراد تعلمها ومن ثم القيام بالعملية التعليمية

فضلا عن ذلك فان هذا بعطي المتعلم القناعة وتولد الرغبة لديه في بذل جهد أكبر للتعلم ولا سيما بعد إدخال مبدأ (Feed Back) أي التغذية الراجعة التي تعطى للمتعلمين وباستمرار كلما تم تحديد نوعية الخطأ بحيث تم تقسيم المتعلمين حسب نوع الخطأ وحسب المستوى لكي يتسنى إعطاء التخذية الراجعة

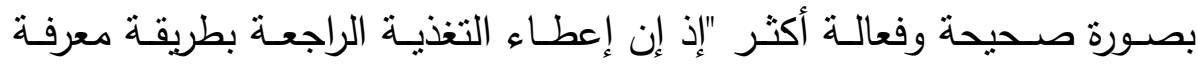
النتائج في الحال تحسن من الانجاز من خلال تعلم المهارات الحركية (9 ( .$(791$

ويؤكد سـمث (Smith berlait)"إن استخدام أسـلوب التعلم الاتقاني كهيكليـة عامـة للـدرس سيؤدي إلى تحسين مسـتوى الأداء وزيـادة كميـة التعلم لكافـة المجموعة المتعلمـة وعكس ذلك فـان مستوى الانجاز قد لا يتطور عند البعض أو قد يتطور ببطء عند استخدام الطريقة التقليدية (YM: V0-VY). 
أمـا مـن حيـث علاقـة الفروق الفرديـة مـن جهـة وتحقيـق الانجـاز الجيد لكافـة

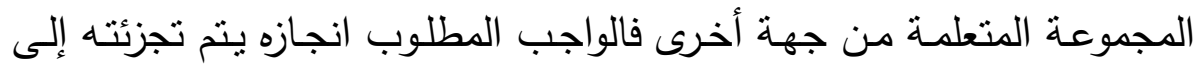
أجزاء عده ولا يتم الانتقال من واجب لآخر إلا بعد إتمام الواجب السابق وفي

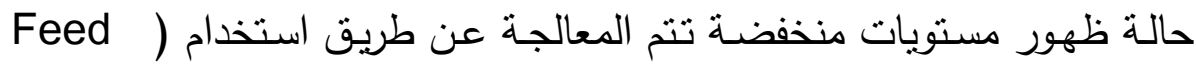
Back المناسبة والتكرارات حيث يتم إتقان المهارة بشكل جيد (9 (: ؟ ؟ ( ).

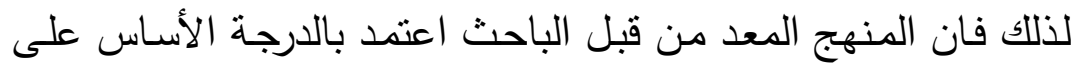
التكرار وكذلك تقسيم المتعلمين إلى فئات حسب مستوياتهم وبالتالي فان التكرار يكون أكثر للمتعلمين الذين لـم يصـلوا إلى مستوى الفئة الأولى، وبهذا فـان

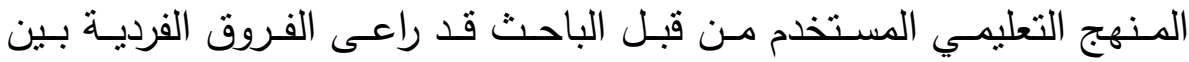
المتعلمين وكذللك استخدام مبدأ مساعدة المتعلم الجيد للمتعلم الأقل مستوى ومن خلال وجود عامل الفروق الفردية بين المتعلمين تم استثمار هذا العامل لتحسين مستوى أداء المتعلمين ضـعيفي الأداء وبإشراف فريق العمل المساعد لكي يتم إيصال المتعلمين إلى مستوى الإتقان عن طريق "استخدام المجموعات الصغيرة

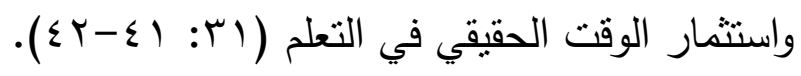

ويتقـق للك مدع نتائج دراسـة كل مـن "محمــ منصــور عبـــ العزيـز

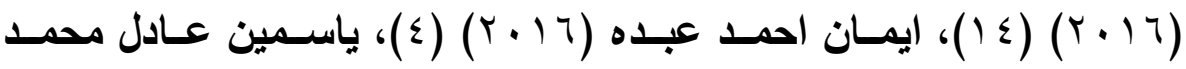

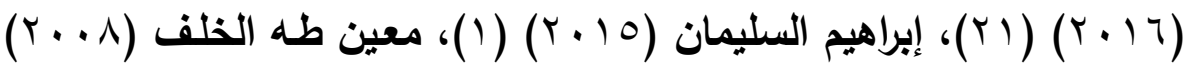

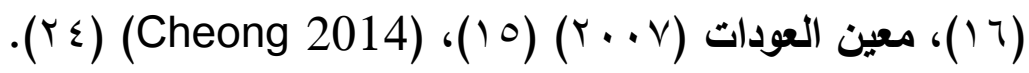
ويذلك نجد أن الفرض الثالث للبحث قد تحقق كليا والذي ينص علي: توجد فروق ذات دلالة إحصائية بين القياسين البعديين للمجموعتين الضـابطة

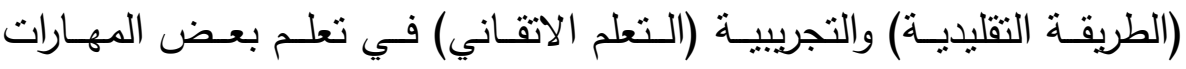
الأساسية بكرة اليد لصالح القياس البعدي للمجموعة التجريبية. كما يتضح من الجدول (V) وعند مقارنة نسبة الاحتفاظ بين المجموعتين الضابطة والتجريبية نجد إن نسبة الاحتفاظ عند المجموعة التجريبية (مجموعة مجلة أسيوط لعلوم وفنون التربية الرياضية 
الإتقان) كانت أكبر من نسبة الاحتفاظ لدى المجموعة الضابطة في المهارات قيد الدراسة وهذا يدل على نجاح منهج التعلم الاتقاني في نطوير تعلم وزيادة

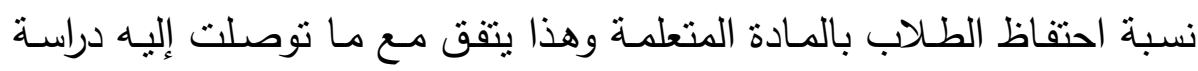

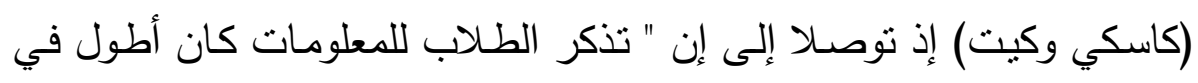

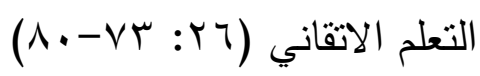

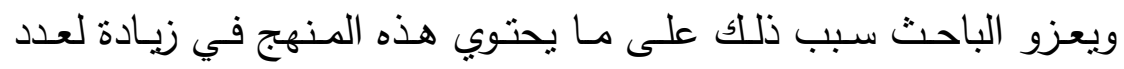

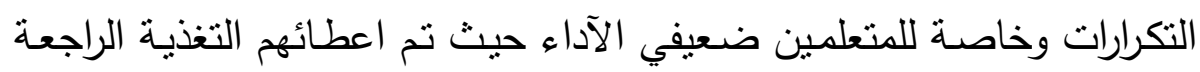

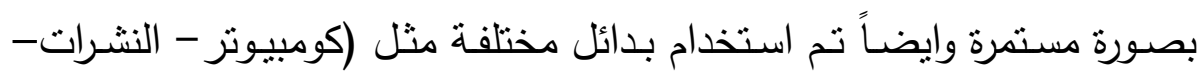
الكتيب) في التكرارات لتجنب الملل ولزيادة التشويق للارس فضلاً عن استخدام

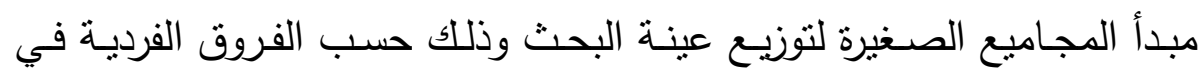

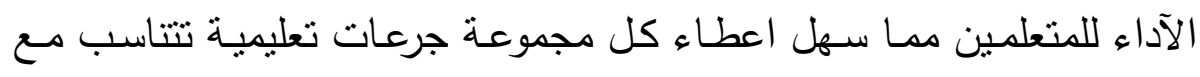

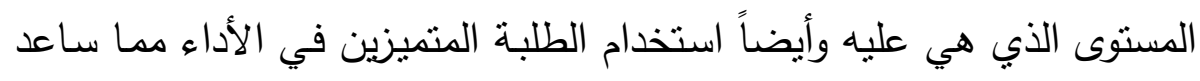

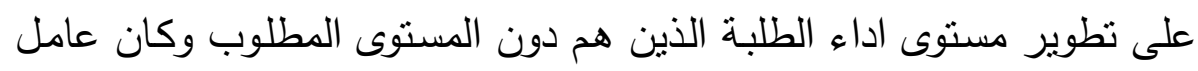

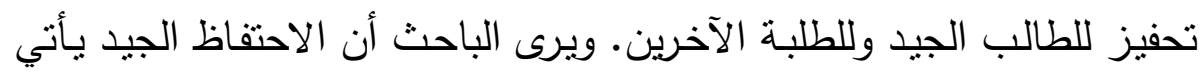

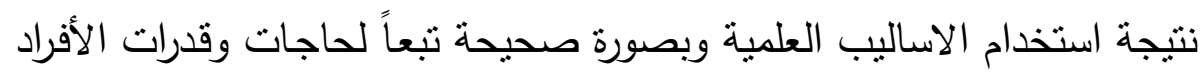

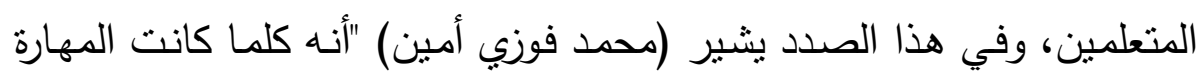

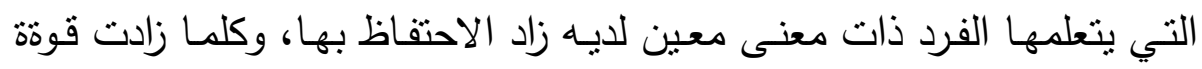

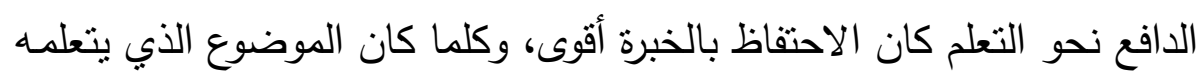

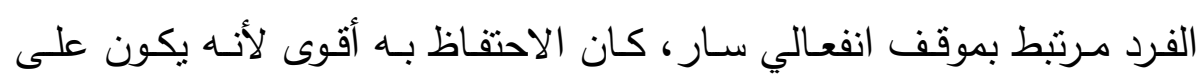

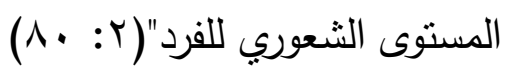

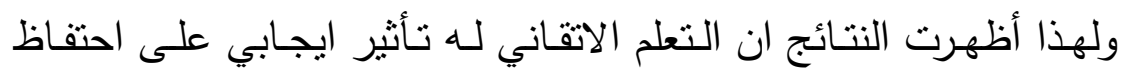
الطلاب بالمادة التي تعلموها. ويذلك نجد أن الفرض الرابع للبحث قد تحقق كليا والذي ينص علي:

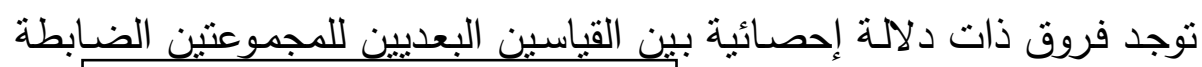
مجلة أسيوط لنطوم وفنون التربية الرياضية البرية 
(الطريقة التقليديـة) والتجريبية (التعلم الاتقاني) في الاحتفاظ لبعض المهارات الاساسية بكرة اليد لصالح القياس البعدي للمجموعة التجريبية.

\section{الاستتتاجات:}

- إن منهج التعلم الاتقاني كان عاملاً رئيساً في تفوق المجموعة التجريبية على المجموعـة الضـابطة في تطوير التعلم والاحتقاظ لبعض المهارات الأساسية بكرة البد قيد البحث.

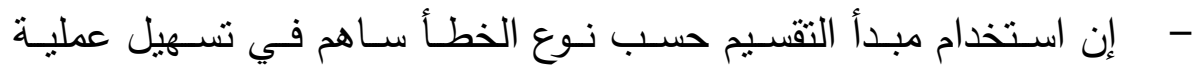
تصــيح الأخطـاء وإعطـاء التغذيـة الراجعـة التصـحيحية المناسـبة لنـوع الخطأ. - - إن استخدام مبدأ التعلم الاتقاني يعزز من كمية الاحتفاظ وهذا ما أكدته نتائج الدراسة. - - إن منهج التعلم الاتقاني لله أثر مهم في زيـادة نسبة احتفاظ المجموعـة التجريبية مقارنة بالمجموعة الضابطة في المهارات قيد البحث.

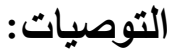
- ضرورة استخدام منهج التعلم الاتقاني في عملية تعلم المهارات الأساسية في كرة اليد في كليات التربية الرياضية.

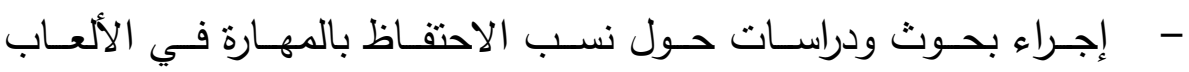

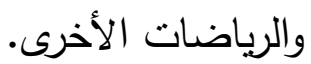

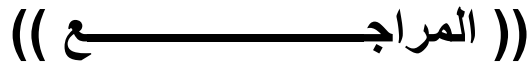

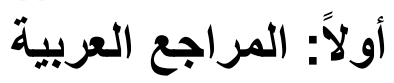

1 - ابراهيم السليمان: نأثير استخدام وسائل تعلم مساعدة في اكتساب واحتفاظ تعلم مهارتي التمرير من الأعلى والتمرير من الأسفل بالكرة

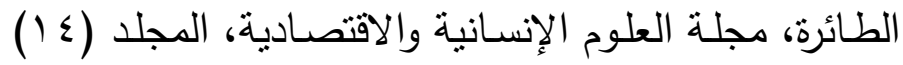

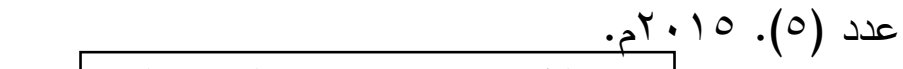
مجلة أسيوط لعلوم وفنون التربية الرياضية 


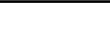

r - احمد أمين فوزي: سيكولوجية التعلم الحركي في المجال الرياضي، منشأة

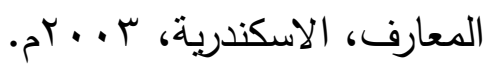

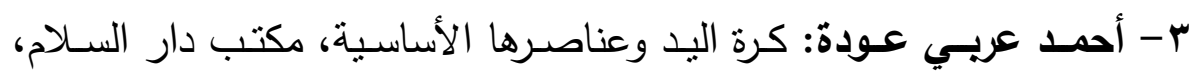

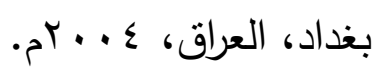

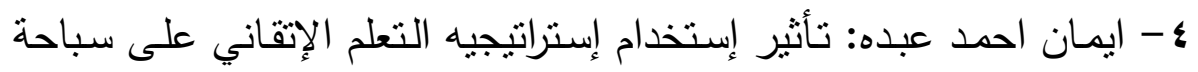
الزحف على الظهر للمبندئين، رسالة ماجستير، كلية التربية

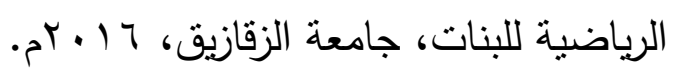

ه- أمير صبري أبو العطا: تأثير برنامج تعليمي باستخدام الوسائط المتعددة التئية على تتمية بعض الجوانب المعرفية والمهارية والوجدانية في تئي

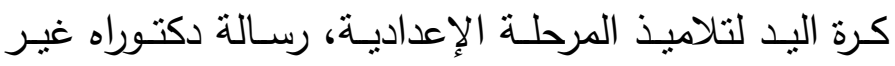

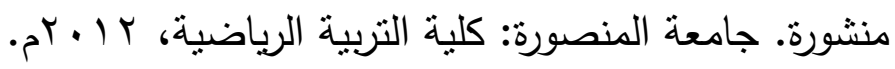

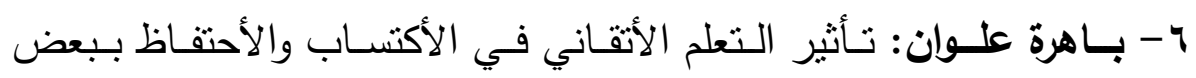

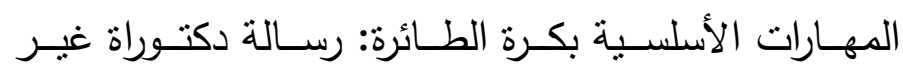

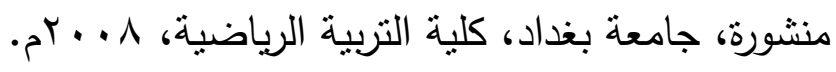

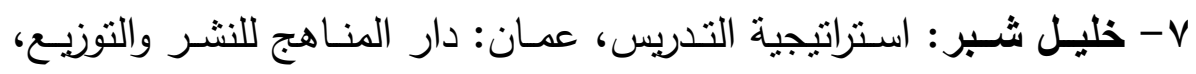

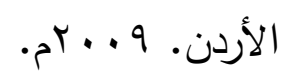

1 شرف محمد عبد القادر : منهج مقترح للتربية الرياضبة للمرحلة الاعدادية

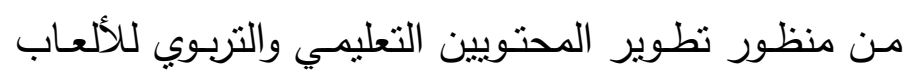

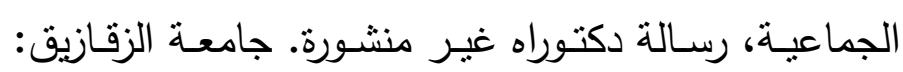

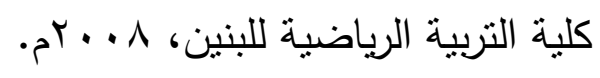

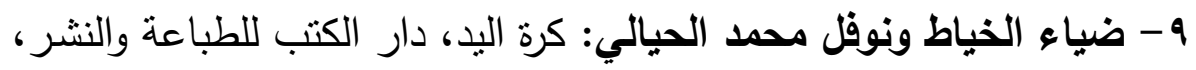

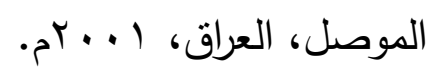

• 1- عبد الحق الاسمر: المعلم واستراتيجيات التدريس، وزارة التربية والتعليم،

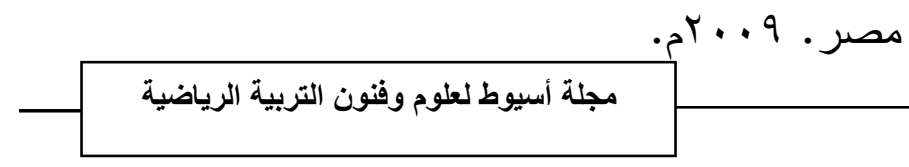


11

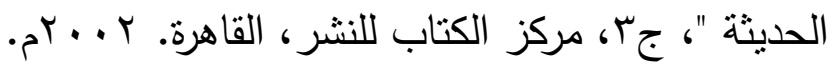
r ا - ليلي السـيل فرحسات: القياس والاختبـار في التربيـة الرياضية. القـاهرة:

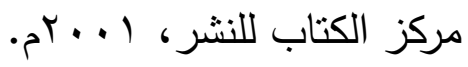

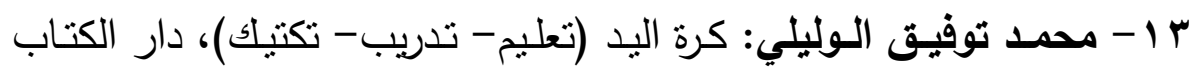

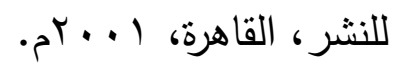

ع ا - محمد منصور عبد العزيز: تأثير استخدام أسلوب التعلم الاتقانى على التى

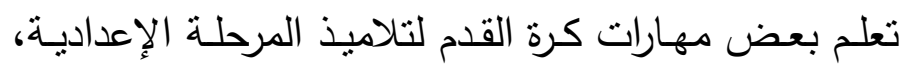
رسالة ماجستير غير منشورة، كلية التربية الرباضية للبنين،

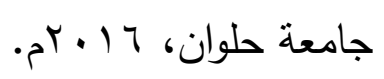

ه - معين العودات: أثز استخدام الأسلوب الاتقاني في تحسين مستوى الأداء

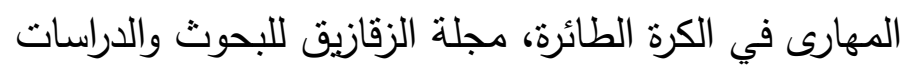

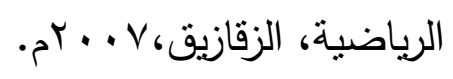

1 ا - معين طه الخلف: تأثير استخدام أسلوب التعلم التعاوني والتعلم الاتقاني

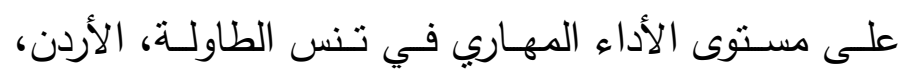

$$
\text { . . . }
$$

V - ناهـدة الـليمي: تأثير التغذيـة الراجعـة الفوريـة في تعلم مهارة الضـرب

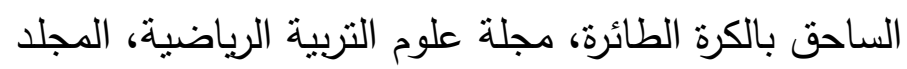

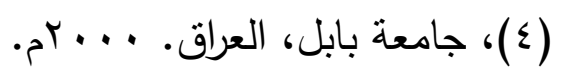

1 1 - هاني أحمد الحسيني: استخدام الهبيرميديا على تعلم بعض مهارات كرة بانئ

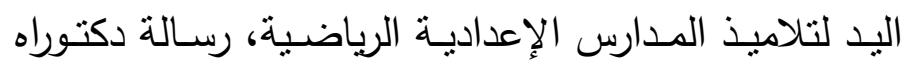

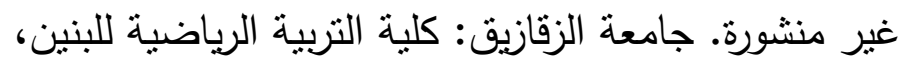

$$
\text { . P }
$$

9 1 - وجيـهـ محجـوب: التـعلم والتعليم والبـرامج الحركيـة، عمـان، دار الفكر للطباعة والنشر ، ب + . rم. 
• ب - وجيـه محجوب: التعلم وجودة التدريب، مكتبـة العـادل للطباعة والنشـر .

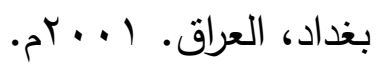

ا ب - ياسمين عادل محمد: فاعلية استخدام استراتيجية التعلم الاتقانى فى تعلم

مهارتى البدءء والدوران فى سباحة الزحف على الـى البطن،

رسالة ماجستير غير منشورة، كلية التربية الرياضية للبنات،

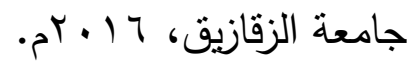

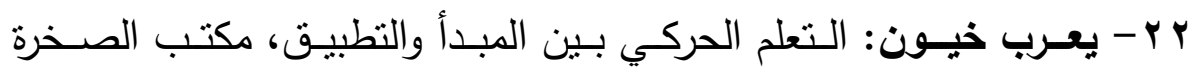

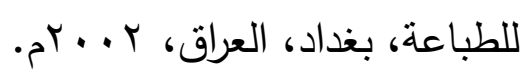

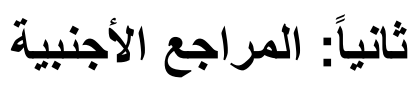

23- Blackmore, c.lguoted by : hairson (and others): effect of tow instructional models skill teaching and mastery learning : (human kinetics, on .teach .phy.ed 1999 ).

24- Cheong, J: The Practicing field Bsket ballskills along the rference continuum: A comparison of practice schedules, Journal of five Sports Science, 11,2 .2014

25- Denise .Dandjacke.s : mastry learning in public school , Valdosta state university .December, 1995.

26- Guskey, and Gates; Synthesis of research of the effects of mastery learning in elementary and secondary classrooms. Educational leadership 48. 1986 
27- Nideffer, R.: The Ethics and practice of applied sport Psychology, Movement Publishers, Ithaca, New York, U.S.A. 2006.

28- Rond, L., Babolhavaeji, F., \& Babolhavaeji, E.: A comparison of blocked and random practice on acquisition of swimming skills, European Journal of sportl. 2012

29- Ryuta. Kawashima; The effect of verbal feedback on motor learning - apet study, avealable on line. Ut http: www - ideal library com. April 2000

30- Schmidt Richard: New concept practice, American of utilizations psychological society vo, 6,nou,july. 2006.

31- Sliver man; S; Proceedings of the per - congress symposium of the 1996 se out international sports science congress. 1996

32- Weiss, m; mecullagh, p. smith, A. \& Berlant, A. Observational Learning and the fearful child :influence of peer models on swimming skill performance psychology claries ponses .Research Quarterly For Exercise and sport ,1988

مجلة أسيوط لعلوم وفنون التربية الرياضية 